Canadian University Music Review

Revue de musique des universités canadiennes

\title{
Voyage Musical aux Asturies
}

\section{Constantin Brailoiu et Laurent Aubert}

Numéro 8, 1987

URI : https://id.erudit.org/iderudit/1014936ar

DOI : https://doi.org/10.7202/1014936ar

Aller au sommaire du numéro

\section{Éditeur(s)}

Canadian University Music Society / Société de musique des universités

canadiennes

\section{ISSN}

0710-0353 (imprimé)

2291-2436 (numérique)

Découvrir la revue

\section{Citer cet article}

Brailoiu, C. \& Aubert, L. (1987). Voyage Musical aux Asturies. Canadian University Music Review / Revue de musique des universités canadiennes, (8), 134-195. https://doi.org/10.7202/1014936ar

All Rights Reserved (C Canadian University Music Society / Société de musique des universités canadiennes, 1986
Ce document est protégé par la loi sur le droit d'auteur. L’utilisation des services d’Érudit (y compris la reproduction) est assujettie à sa politique d'utilisation que vous pouvez consulter en ligne.

https://apropos.erudit.org/fr/usagers/politique-dutilisation/ 


\title{
VOYAGE MUSICAL AUX ASTURIES
}

\author{
Constantin Brailoiu
}

Texte et musique transcrits, annotés et préfacés par Laurent Aubert

\section{Préface}

Le texte que nous présentons ici est la transcription de deux conférences données par l'ethnomusicologue roumain Constantin Brailoiu à la Radio suisse romande les 19 et 26 février 1953 sur la musique des Asturies, région du nord de l'Espagne. Ces conférences s'inscrivent dans un cycle de vingt-six causeries dont la Radio avait chargé Brailoiu entre 1951 et 1954,1 en vue de présenter à ses auditeurs la Collection universelle de musique populaire enregistrée, une série de disques 78 tours qu'il éditait depuis 1951 pour le compte des Archives internationales de musique populaire (AIMP) de Genève sous les auspices de l'UNESCO.2

La Collection universelle ayant récemment été rééditée, il nous a paru opportun de faire connaître aux lecteurs de cette revue les conclusions que Brailoiu devait tirer de son "Voyage musical aux Asturies", effectué à l'été 1952, et dont la teneur était jusqu'à aujourd'hui restée inédite. Les deux émissions ici transcrites sont en effet les seules du cycle radiophonique mentionné n'ayant pas pour axe un disque de la Collection universelle. On peut toutefois supposer que, si le destin lui en avait laissé le temps, Brailoiu aurait au moins consacré un disque aux découvertes musicales, à son sens prodigieuses, qu'il avait faites aux Asturies et dans les régions avoisinantes. Mais la Collection fut interrompue par son décès, survenu le 20 décembre 1958, alors qu'il venait d'en publier le quarantième disque, consacré à quelques aspects de la musique populaire allemande.

1 Les deux émissions sur les Asturies sont les dix-neuvième et vingtième de la série. Elles portent les références RSR MS/ 53/168 et 169. Pour une liste complète et une analyse globale de ces émissions, cf. Nattiez (1984:15-21).

2 La Collection universelle de musique populaire enregistrée a été établie par Constantin Brailoiu avec les Archives internationales de musique populaire (AIMP) de Genève et le concours de l'UNESCO de 1951 à 1958 ; elle comportait quarante disques 78 tours $25 \mathrm{~cm}$. Elle a été rééditée en 1984 par les AIMP, avec notamment la collaboration de l'Université de Montréal, sous forme d'un coffret de six disques 33 tours $30 \mathrm{~cm}$. accompagné d'une importante plaquette (réf. VDE 30-425/430). 
Cette mission aux Asturies fut l'une des rares expéditions de Brailoiu sur le terrain après son départ de Roumanie en 1943. A notre connaissance, il n'en réalisa que deux autres, toutes deux en Yougoslavie : l'une en 1951, dans la région de Skoplje, portant sur la musique des Serbes de Macédoine, et l'autre en 1955, parmi la population roumanophone du Banat yougoslave. ${ }^{2}$ L'idée d'une campagne de recherche aux Asturies, hors de son aire de spécialisation, s'inscrivait pour Brailoiu dans une "tentative scientifique nouvelle", dont un des buts était, comme il le dit ici, de "multiplier les contacts de pays à pays, afin de mettre les spécialistes à même de prendre connaissance, dans leur travail actif aux côtés de collègues étrangers, des réalités autres que la leur propre". 4 L'article que voici revêt un intérêt particulier à cet égard, car il est le seul témoignage des fruits retirés par Brailoiu de sa collaboration avec deux éminents musicologues : Marius Schneider, le grand maître allemand de la symbologie musicale, alors directeur de la section Folklore de l'Instituto Español de Musicología de Barcelone, et Manuel García Matos, professeur au Conservatoire de Madrid, un des meilleurs spécialistes des musiques populaires espagnoles, que Schneider lui avait recommandé.

Brailoiu avait fait la connaissance de Schneider quelques années auparavant, lors de congrès internationaux; il appréciait les grandes qualités humaines et intellectuelles de son collègue allemand. De nombreuses affinités allaient rapprocher les deux érudits: leur intérêt commun pour les polyphonies "primitives", leurs études sur le rythme, leurs vues sur les relations entre musiques savantes et musiques populaires, ou encore leur goût partagé pour l'application étendue de la méthode comparative - goût d'ailleurs relativement récent chez Brailoiu, si l'on se réfère à ses monographies roumaines. 5 Brailoiu avait dû être impressionné par l'ampleur peu commune de la vision de Schneider, lequel ne craignait pas d'inclure dans son approche du fait musical ou, plus globalement, "audible", des données relatives à la mythologie, à la cosmogonie, voire au rôle "agissant" de la musique dans les rites des civilisations traditionnelles.6 Or, Brailoiu n'avait jamais eu l'occasion de se pencher sur ces questions dont - certains de ses écrits l'attestent - il ressentait cependant la prééminence.

3 Brailoiu réalisa également une série d'enregistrements de chansons et formulettes enfantines à Genève en 1946. Une description de ces diverses missions figure dans notre article "La quête de l'intemporel" (1985: 46-50). Cf. infra.

5 Voir notamment Brailoiu (1960 et 1973).

6 Parmi l'oeuvre considérable de M. Schneider en ce domaine, citons les études se rapportant plus spécifiquement à l'Espagne dont Brailoiu avait pu avoir connaissance en 1951 : Schneider (1946a, 1946b, 1948 et 1949). Pour un complément bibliographique, voir, par exemple, Günther (1969). 
Il approcha donc son collègue allemand pour lui proposer d'entreprendre une mission commune, dans ce qu'il jugeait être des conditions optimales :

[...] il nous est apparu que la cause qui nous occupe serait servie de manière particulièrement efficace par la collaboration sur le terrain même d'équipes restreintes composées de chercheurs de plusieurs pays. Pareille association, en effet, permettrait non seulement le contact per-sonnel entre chercheurs, si précieux, scientifiquement et moralement parlant, mais également l'application pratique des règles de travail établies d'un commun accord [...] Nous estimons également que la participation à ces travaux d'un érudit tel que vous et l'intérêt hors pair que, de tout point de vue, offre la musique populaire de l'Espagne sont les gages certains d'un succès scientifique certainement appelé à un retentissement considérable. ${ }^{7}$

Quant à M. García Matos, il était alors un des proches col laborateurs de Schneider, qui venait d'éditer son Cancionero popular de la provincia de Madrid (1951). Il collaborait aussi régulièrement à l'Anuario musical de l'Institut de Barcelone, auquel il a fourni d'importantes contributions, notamment sur les origines $d u$ cante flamenco (1950) et sur l'organologie (1954, 1956). García Matos était un homme rompu aux techniques de terrain, ayant déjà parcouru la plupart des provinces espagnoles pour en immortaliser les manifestations musicales les plus caractéristiques. Il sentait l'urgence d'une collecte extensive destinée, sinon à en maintenir la tradition, du moins à préserver la mémoire de musiques irrémédiablement menacées de dissolution à plus ou moins brève échéance par la propagation de la culture urbaine dans les campagnes espagnoles.

L'oeuvre discographique de García Matos dans ce domaine est considérable. Il publia, en 1960 et en 1971, deux Anthologies du folklore musical d'Espagne, et travaillait à sa réalisation majeure, Magna antología del folklore musical de España, lorsque la mort l'emporta le 26 août 1974. Cette publication parut en 1979 sous les auspices du Conseil international de la musique de l'UNESCO, sous forme d'un volumineux coffret de dix-sept disques 33 tours $30 \mathrm{~cm}$., contenant 330 enregistrements, soit au total plus de dix heures de musique.

Une équipe idéale paraissait donc réunie pour cette expédition dont l'un des buts était, à travers la collecte d'exemples musicaux significatifs principalement aux Asturies, de confirmer l'inanité de la "thèse arabisante" sur l'origine des musiques populaires espagnoles, thèse à laquelle Schneider s'était déjà attaqué dans une étude antérieure (1946a).

7 Lettre de C. Brailoiu à M. Schneider, datée du 7 avril 1951. 
La reproduction des deux émissions que Brailoiu a consacrées à ce voyage est intéressante à plus d'un titre. Elles ont en effet, comme le souligne JeanJacques Nattiez, un caractère didactique, voire scientifique, accusé : "[...] Brailoiu lit un texte, fait un véritable cours et n'a pas peur d'user de termes musicologiques techniques : par chance pour nous, il fait ce qu'on considérerait aujourd'hui comme de la mauvaise radio!" (Nattiez 1984 : 15). On voit apparaître au cours du texte l'application au domaine espagnol, et plus particulièrement asturien, de plusieurs des thèmes de prédilection de Brailoiu, tels que l'étude des échelles, celle des rythmes, le "chant long",8 ou encore la distinction entre les musiques populaires à proprement parler - c'est-à-dire pratiquées par des amateurs généralement paysans - et leur cristallisation par des musiciens professionnels - tsiganes ou d'origine urbaine -, signe, selon lui, de leur décadence.

Le cadre limité de ces deux émissions ne permettait malheureusement pas à Brailoiu d'aborder toutes les questions suscitées par une matière aussi riche. Les arguments qu'il oppose à la thès e "arabisante" sont certes probants, mais ils n'apportent en définitive que peu d'éléments nouveaux par rapport aux études antérieures de Schneider (1946a) et de García Matos (1950). On aurait aimé qu'il se prononce par exemple sur la thèse "celte" ou "celto-ibère", appuyée par de nombreuses investigations aux Asturies et en Galice, 9 ou qu'il éclaircisse certaines données restées obscures concernant les rapports entre musique asturienne et musique andalouse, rapports pourtant attestés - au moins dès la Reconquista - par d'importants mouvements migratoires des Asturies en Andalousie, en particulier à Cádiz et à Séville. 10

Il aurait aussi été intéressant que Brailoiu développe quelque peu la question de l'organologie, qui se situe pourtant au centre du débat dans lequel s'inscrit cette "causerie". On sait en effet que la quasi totalité des instruments de musique populaire espagnols sont de souche arabe - selon Arcadio de Larrea, seuls deux types de flûtes, le chistu (ou txistu) et le flaviol, auraient une origine non-arabe (1978:3). La cornemuse elle-même, sacrée "reine du Nord" par Brailoiu, porte en espagnol le nom de gaita, une altération de l'arabe al-ghaita, qui désigne encore aujourd'hui le hautbois au Maghreb et en Afrique

8 Le "chant long" est un chant au rythme non mesuré. Dans son étude sur Brailoiu, Nattiez répertorie les différentes définitions qu'en a données le musicologue roumain (1984 : 17, 4a). Nous retiendrons celle-ci : "Une longue mélopée, librement construite à l'aide de quelques formules mélodiques, sans cesse reprises, alternées, variées, enjolivées." (Serbes, disque 8 ; réédition : AIMP, IV A 1.)

9 Cf. n. 22 et 23.

10 Cf. D. Modesto Gonzalez Cobas (1975 : 75-83). 
de l'Ouest. Comment notre auteur expliquait-il que cette filiation instrumentale et étymologique, attestée jusqu'aux Asturies, fût accompagnée par l'absence de toute influence mauresque dans les techniques de jeu?

A ce propos, un autre sujet n'est ici qu'effleuré : celui de l'éventuelle influence espagnole sur la musique arabe, et plus précisément maghrébine, sujet qui a entretemps fait couler beaucoup d'encre. 11 Après avoir reconnu sa méconnaissance de la (des) musique(s) arabe(s), Brailoiu ne fait que suggérer de façon sibylline qu'"on pourrait imaginer une opération téméraire, consistant à retrouver cette musique populaire arabe, que nous ignorons presque, à travers l'andalouse."12 Qu'entend-il au juste par là, et à quelle musique populaire arabe fait-il allusion? S'il veut parler de la musique dite "arabo-andalouse" (al-cala al-andalusiya), laquelle, bien qu'ayant pris forme sur le sol andalou, n'a pas pour autant été nécessairement influencée par les traditions indigènes, il ne s'agit pas, en tout état de cause, d'une musique "populaire" ; et s'il se réfère aux différentes musiques maghrébines qu'on est en droit de taxer de "populaires", elles sont, dans l'ensemble, de souche plus berbère qu'arabe. Brailoiu avait pourtant tout le moins accès, à cette époque, aux travaux d'Alexis Chottin (notamment 1938) qui mettent clairement en évidence l'originalité de la musique berbère en regard de la musique arabe.

Mais, peut-on objecter, il ne s'agit pas ici, en définitive, d'une étude à prétentions scientifiques, mais d'un travail de vulgarisation sous forme de simples émissions de radio, lesquelles sont d'ailleurs d'un très haut niveau. Cependant, dans le cas présent, on aurait souhaité que cette unique expédition de Brailoiu dans la péninsule ibérique débouche sur autre chose, qu'elle suscite une nouvelle orientation dans ses recherches, une nouvelle application, voire un élargissement, des méthodes d'investigation qu'il avait élaborées en Roumanie. Mais, à part quelques notes de terrain manuscrites qui n'ajoutent rien à la teneur de ces deux conférences, Brailoiu n'a laissé aucun écrit sur sa mission aux Asturies.

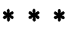

Voici le découpage que nous proposons de ces deux émissions radiophoniques sur le "Voyage aux Asturies" :

\section{Considérations générales}

a. Résumé de la vision commune de la musique espagnole (réf. : P. Aubry).

11 Voir, entre autres, M. Schneider (1946a : 56 s.).

12 Cf. infra. 
b. Diversité musicale de l'Espagne (réf. : P. Aubry, H. Anglés, M. Schneider).

2. Prémisses et buts de l'expédition de 1952

a. Méthodologique : contacts internationaux entre chercheurs (Espagne: M. García Matos; Allemagne : M. Schneider; Roumanie : C. Brailoiu).

b. But immédiat : travail de terrain visant à l'approfondissement de la connaissance de la musique asturienne.

c. Justification : existence de travaux préparatoires (M. García Matos).

d. Intention : réfutation de la théorie "arabisante".

3. Argumentation

a. Les échelles : absence en Espagne d'un chromatisme "à l'arabe" (réf. : magâm Hijaz); fréquence des degrés mobiles (aigus dans l'échelle ascendante, graves dans l'échelle descendante) ; fréquence des intervalles non tempérés.

b. L'ornementation vocale : pas spécifiquement arabe; pr\& eac.sente "là où les Arabes n'ont pu étendre leur conquête".

c. Le chant "long" : id.

d. L'émission vocale : nasale et gutturale chez les Arabes, mais non chez les Andalous ; ouverte, au timbre claironnant chez les Asturiens.

e. Les instruments : présence, dans chaque région, d'instruments autochtones ou d'origine étrangère, mais non arabe.

f. Les rythmes : conceptions rythmiques et métriques distinctes, en Espagne, de celles des Arabes; présence du rythme aksak et du giusto syllabique bichrone (non mentionné dans le texte, mais attesté par les exemples musicaux). 13

g. Les structures musicales : spécificités régionales.

h. La persistance de composantes pré-chrétiennes : notamment aux Asturies.

i. Le comparatisme : références aux musiques balkaniques, hongroise, irlandaise, kabyle, turque, grecque, serbe, roumaine, touarègue, suisse

13 Brailoiu explique dans deux articles la signification qu'il donne à ces termes. Ces articles ont été republiés dans Brailoiu (1973 : 301-340 et 151-194). 
alémanique, en plus de celles des différentes régions espagnoles et de celles des Arabes.

4. Itinéraire musical

a. Fictif14 :

Salonique (exemple musical 1)

Malaga (ex. 2)

Salamanque (ex. 3)

Séville (ex. 4)

Valence (ex. 5)

Ibiza (ex. 6-7)

Catalogne (ex.8)

Pays Basque (ex. 9)

Vieille-Castille (ex. 10)

b. Réel :

Vieille-Castille (ex. 11-12)

Asturies : région de Luarca (ex. 13-15)

région de Llanes (ex. 16-19, 22)

région d'Oviedo (ex. 20-21)

Laurent Aubert

14 Par "itinéraire fictif", il faut entendre la partie des émissions ne se rapportant pas au voyage effectué par Brailoiu et ses collègues. L'itinéraire "réel", lui, correspond au trajet qui les mena de Madrid aux Asturies en 1952 ; les enregistrements afférents ont, pour la plupart, été réalisés par les trois musicologues sur le terrain. 


\section{VOYAGE MUSICAL AUX ASTURIES}

Vers 1907, au retour d'un voyage en Espagne, le musicologue Pierre Aubry écrivait à peu près ceci :

Allez là-bas et revenez avec une riche moisson de chants populaires récoltés en Castille, en Galice, en Estrémadure, en Andalousie, et montrez votre bulletin à quelque compositeur de rhapsodies ou de caprices espagnols, à n'importe quel dilettante, voire même à un critique averti. Vous verrez leur sourire, et leur pensée secrète sera que ces chants populaires n'ont aucun caractère espagnol. C'est qu'il $\mathrm{y}$ a du chant populaire à l'usage du music-hall dans toutes les capitales d'Europe. Il a ce trait particulier d'accompagner toujours une danseuse habillée de rouge, et son partenaire vêtu en torero. On l'appelle uniformément bolero, fandango, habanera ou jota sur les programmes des cafés-concerts. Vainement on chercherait, dans les provices les plus authentiques de l'Espagne, ces bailes populares entendus à Paris, à Londres ou à Berlin. C'est un produit national destiné uniquement à l'exportation. ${ }^{1}$

Et plus loin, Aubry ajoute qu'il y a autant d'Espagnes qu'il y a de provinces, et qu'il faudrait s'attacher séparément à chacune d'elles, alors que l'on a fait de l'Andalousie toute l'Espagne.

C'est parler d'or ; nous reconnaissons bien ce morcellement dialectal saisissant, que l'histoire de notre vieux continent a provoqué même dans de très petits pays, comme la Suisse, et qui a déjà amené la Collection Universelle à revenir sur ses pas, en Roumanie, en Italie, en Yougoslavie, et à prévoir semblable retour pour la France par exemple, ou pour la Grèce.

La prodigieuse diversité musicale de l'Espagne est un fait, et Aubry a bien raison de le souligner. On a attribué cette diversité aux races nombreuses - Celtes, Ibères, Finnois, Arabes, Berbères - qui ont

1 Pierre Aubry (1907-08). 
successivement ou simultanément habité la péninsule, et Monseigneur Anglés n'hésite pas à remonter, par delà les Wisigoths, jusqu'aux Grecs anciens. ${ }^{2}$ C'est de quoi nous nous garderons bien de discuter. De l'état de choses présent, nous nous sommes borné à tirer un enseignement pratique, ce qui nous interdisait absolument d'envisager un disque espagnol autre que régional. Mais l'absence des phonographes ${ }^{3}$ indispensables a impliqué la nécessité d'un déplacement qui permit d'en rapporter ; et c'est l'itinéraire de l'expédition organisée à cette fin en été 1952 que vous êtes invités à suivre en pensée. Une fois la campagne de recherche reconnue inévitable, il fut décidé de saisir l'occasion qui s'offrait, aux fins d'une tentative scientifique nouvelle. Son but ne peut être exposé ici que dans ses très grandes lignes. Il suffira de rappeler qu'un très grand nombre de thèses soutenues dans le passé quant à l'art populaire, sa nature, ses origines, porte la marque trop visible d'une expérience purement personnelle et locale. De l'état fortuit de cet art en un moment et en un lieu précis, des savants de grande autorité ont cru pouvoir tirer des lois générales, applicables sensément toujours et partout. ${ }^{4}$ Et le moins que l'on puisse dire est que, leur prestige aidant, les savants en question n'ont pas fait que du bien, malgré la quantité d'idées neuves qu'ils ont remuées. Il apparaissait donc hautement souhaitable de multiplier les contacts de pays à pays, afin de mettre les spécialistes à même de prendre connaissance, dans leur travail actif aux côtés de collègues étrangers, des réalités autres que la leur propre. C'est pourquoi l'Institut espagnol de musicologie et les Archives internationales de musique populaire de Genève, auxquelles est confiée l'édition de la Collection universelle de l'UNESCO, ${ }^{5}$ ont convenu, avec l'approbation et l'assistance de cette dernière, de déléguer une équipe de trois chercheurs de nationalité différente, comprenant le professeur García

2 Voir notamment Higini Anglés (1964 : 54-56) et H. Anglés et J. Pena (1954).

3 Brailoiu veut probablement dire "phonogramme", et non "phonographe".

4 Les principaux défenseurs de la thèse arabisante étaient Henry George Farmer (notamment 1929, 1930) et Julián Ribera y Tarragó (1922, 1927).

5 Cf. n. 2. 
Matos, du Conservatoire de Madrid, le musicologue allemand bien connu Marius Schneider, et l'éditeur de la Collection. Restait à choisir la province d'Espagne qu'ils visiteraient, et après mûre réflexion, leur choix se porta sur les Asturies, la vieille principauté du nord. Trois raisons importantes en ont décidé ainsi : tout d'abord, la musique populaire asturienne est encore peu connue ; ensuite, les conditions matérielles d'une exploration fructueuse semblaient assurées par des travaux préparatoires ; enfin, parce que de l'avis de ceux qui s'y préparaient, c'était là que l'on pouvait espérer acquérir quelques notions positives sur un problème capital de la musique populaire espagnole.

On a fait de l'Andalousie toute l'Espagne, protestait Aubry. Mais au vrai, c'est encore bien trop peu dire. Schneider, plus tard, écrira que "lorsqu'on examine la littérature existante sur l'histoire de la musique espagnole, on constate une tendance absolument épidémique à considérer la musique espagnole comme une création arabe". 6 Ainsi pensent en effet la plupart des gens. Ce qui semble à un Français, à un Anglais ou à un Allemand, original ou savoureux, ou exotique dans le folklore musical de l'Espagne, est à leurs yeux essentiellement andalou, et le charme de l'andalou ne serait dû à son tour qu'à ce qu'il contient de résidus arabes ; ce qui vaudrait d'ailleurs, mais dans une moindre mesure, pour le pays tout entier. Le bien-fondé de cette opinion doit encore être vérifié soigneusement, et ne pouvait l'être mieux, pensions-nous, que dans les Asturies, antique rempart des Chrétiens, où jamais Maure ne mit le pied. La découverte de ressemblances fondamentales avec le cante jondo, le "chant profond", présumé mauresque, du midi, ne pouvait manquer d'affaiblir la théorie arabisante, alors que des différences tranchantes l'auraient sinon confirmée, du moins laissée subsister jusqu'à plus ample informé. Or, lorsqu'on demande les arguments sur lesquels se fondent les défenseurs de l'arabisme, on a tôt fait de se rendre compte que, tout bien pesé, il s'agit bien plutôt d'impressions, de sensations, d'un effet d'ensemble, que d'une analyse objective. Si l'on insiste, on entendra le plus souvent invoquer le chromatisme, c'est-à-dire les gammes à intervalles augmen-

6 Marius Schneider (1946a : 31). 
tés, et l'allure mélismatique, c'est-à-dire fleurie, ornée, des mélodies, laquelle a longtemps passé, même dans le chant grégorien par exemple, pour un caractère foncièrement oriental. Ces deux critères, supposés décisifs, venant à manquer en Aragon, en Galice ou en quelqu'autre endroit, on trancha la question en déclarant, comme le déplorait Aubry, qu'on n'a plus affaire là à rien d'espagnol.

Regardons-y tout de même d'un peu plus près. Pour commencer, le chromatisme, à supposer qu'il foisonne, dénoterait à coup sûr l'influence de la musique arabe, et qui plus est, de la musique arabe savante. On pourrait alors certifier que l'un des magâm, ou "types mélodiques" de celui-ci, à savoir sans doute celui qu'on nomme Hijaz, a pénétré dans le peuple et s'y est perpétué, ainsi qu'il est arrivé dans les Balkans et en Hongrie. Mais est-ce bien le cas ? On ne peut aucunement le soutenir. Des anciennes chansons lyriques et d'anciens trésors de romances, de ballades et de styles légendaires chantés, dont l'Espagne est si riche, les Juifs ont emporté dans leur exil bien des restes précieux où, après des siècles de cohabitation avec des Orientaux, la plus puissante loupe musicologique ne découvrirait ni la moindre affection chromatique, ni même quoi que ce soit de proprement oriental.

Ainsi vous souvient-il peut-être encore de la tragique histoire des "Nouveaux-nés substitués" de notre neuvième disque, recueillie à Salonique $^{7}$ (cf. exemple 1).

Non qu'il n'y ait aucune trace d'échelle chromatique en Espagne ; mais ce qui nous frappe surtout, fût-ce au café-concert, c'est tout autre chose, à savoir une formule, dont d'ailleurs de grands compositeurs tels que Debussy ou Ravel n'ont pas dédaigné la vertu colorante : une sorte de lieu commun mélodique que l'on voit apparaître dès le XVIIe siècle dans les livres de guitare. Ce qui le caractérise si fortement, c'est la mobilité de l'un de ses sons, aigu à la montée, grave à la descente. Cela est dans toutes les mémoires, dans toutes les oreilles (cf. exemple 2).

7 Ballade : Partos trocados ("Les nouveaux-nés substitués"), enregistrée en 1951 par Léon Algazi à Salonique (édition originale : CU 9 II b ; réédition : AIMP III B 7). 
Que ce signe mélodique, encore que non chromatique, est bien distinctif, on ne saurait en avoir meilleure confirmation que par le rapprochement avec une danse chantée de Salamanque, où tout rentre dans l'ordre qui nous est coutumier (cf. exemple 3).

$\mathrm{Si}$, du chromatique, nous passons maintenant au style vocal orné, nous accorderons assurément qu'il n'est nulle part plus florissant que dans le midi de l'Espagne, et qu'on aurait grand-peine à trouver, où que ce fût, des gosiers plus agiles. Mais les Arabes y sont-ils nécessairement pour quelque chose ? Nous sommes tombé sur un bel canto campagnard à vocalises en Irlande, ${ }^{8}$ et à l'inverse, des documents récents dignes de toute confiance nous apportent la preuve irréfutable que les Kabyles, de toute évidence plus proches des Arabes, ne serait-ce que topographiquement parlant, pratiquent une diction dépouillée, syllabique, ignorant absolument la fioriture et la roulade. ${ }^{9}$ Par ailleurs, il y a lieu, particulièrement en vue de ce qui nous attend dans les Asturies, de rappeler que la musique populaire andalouse est, dans l'ensemble, le fait de chanteurs plus ou moins ou tout à fait professionnels, en majorité Bohémiens ou Gitans, Gitanos. Certains donnent de grands récitals et font des tournées, écoutés par une foule muette. ${ }^{10} \mathrm{Ce}$ n'est pas qu'il soit impossible de rencontrer des gens du peuple, des "civils", si l'on peut dire, capables de nous délecter de longues heures durant par d'inoubliables performances de cante jondo ; mais dans ce cas même, l'ombre du musicien de métier se profilera sans faute, d'une manière ou d'une autre, dans le fond du tableau, soit que le nom illustre d'un incomparable modèle vienne à être prononcé avec respect par le chanteur dilet-

8 Brailoiu a édité une de ces ballades : The Hay Rope ("La corde de foin"), (CU 12 I a ; AIMP V B 1).

9 L'auteur se réfère ici aux chansons kabyles dont il a eu connaissance, celles enregistrées par Jean Servier chez les Kabyles At Yänni du Djurdjura, Algérie, en 1952 (CU 35 ; AIMP I B 10-15).

10 L'audience du cante flamenco est, en général, loin d'être "muette". Au contraire, elle manifeste tcujours vivement son émotion par ses célèbres jaleos (Olé !), qui ponctuent chaque moment particulièrement intense de l'interprétation d'un chant. 
tante au cours de l'entretien, soit que lui-même, un jour de disette, s'essaie à tirer profit de ses talents dans quelque café.

Régulièrement, les étoiles du chant andalou s'accompagnent ${ }^{11}$ ou se font accompagner à la guitare, sans aucun doute empruntée au milieu citadin, et en tirent des accords parfaits, évidemment citadins aussi. Comment expliquer cette situation singulière ? Apparemment d'une seule façon : elle représente probablement un état de décadence du chant populaire vocal, hérissé par nature de difficultés techniques, et passé petit à petit, à cause de ces difficultés, aux mains d'une classe experte, qui en a fait son gagne-pain. Un seul genre fait exception dans une large mesure. C'est la saeta, littéralement "flèche", chantée sans accompagnement sur le passage des solennelles processions de la Semaine Sainte, escortées de fanfares et de tambourinaires municipaux. Pathétiques déplorations de la Passion, que le premier venu ou la première venue peut lancer soit du haut d'un balcon, soit dans la rue même. ${ }^{12}$ Dès que le premier son s'en fait entendre, le cortège s'arrête net, on fait silence, et seuls les tambours contin uent à ponctuer sourdement la douloureuse cantilène (cf. exemple 4).

La saeta est un de ces chants dits "longs", à demi improvisés, que les Arabes connaissent probablement, mais que nous avons surtout rencontrés en Turquie, Grèce, Serbie, Roumanie, chez les Touaregs, et auxquels nous avons cru pouvoir rattacher également le briolage des pâtres français et la prière des bergers catholiques suisses, le Betruf. ${ }^{13}$

11 Traditionnellement, le chanteur ne s'accompagne jamais lui-même à la guitare.

12 Selon Marius Schneider (1946a : 60), la saeta serait le seul exemple, encore qu'incertain, d'emprunt à la musique arabe : "Les autres similitudes entre musiques arabe et espagnole sont des éléments méditerranéens communs, qui ne sont jamais explicables par l'apport arabe, [...] les éléments communs entre musiques espagnole, arabe, persane et indienne doivent remonter à une époque bien antérieure à l'invasion musulmane." Sur l'origine de la saeta, voir aussi A. de Larrea (1949 : 117-122).

13 Turquie : cf. CU 13 II (AIMP II A 2) ; Grèce : cf. CU 10 (AIMP III B 1-2) ; Serbie : cf. CU 8 II a (AIMP IV A 2) ; Touaregs : cf. CU 11 (AIMP 
Rien ne nous autorise à la qualifier de spécifiquement arabe. Disons bien, au surplus, que la comparaison hispano-arabe ne peut se référer qu'à la musique arabe savante, dont nous avons quelque connaissance, et non à la musique populaire, sur laquelle de rares lumières n'ont été jetées que ces tout derniers temps. Or, les traits saillants de celle-là sont - grosso modo et mis à part certains préludes et interludes libres, mais dissemblables du chant long - : d'abord, la composition par association constante d'une mélodie à un rythme obstiné ; ensuite, des échelles très divisées ; enfin, une émission systématiquement nasale ou gutturale, toutes choses qu'on chercherait vainement en Andalousie. $\mathrm{Au}$ rebours, on pourrait imaginer une opération téméraire consistant à retrouver cette musique populaire arabe, que nous ignorons presque, à travers l'andalouse. On aurait peut-être une faible chance d'y parvenir si tout le territoire de domination maure présentait un style musical rigoureusement unitaire. Voyons un peu : prenons au hasard une aubade de la région de Valence (cf. exemple 5).

Certes, des parentés avec l'Andalousie sont indéniables, mais déjà la forme se clarifie, la prolifération des ornements diminue, l'expression tonale diffère, et les instruments nous orientent plutôt vers la Catalogne. Et que dire des Baléares, particulièrement d'Ibiza, d'où nous arrive justement un étonnant noël, suivi d'un refrain instrumental dansé ? Il n'y a plus là qu'un récitatif absolument nu, achevé par une sorte de sanglot étrange, un bêlement plutôt (cf. exemple 6).

Plaçons entre parenthèses deux danses ibiçaines qui nous parviennent en même temps. Nous n'aurons peut-être plus l'occasion d'y revenir. Elles sont rythmées au moyen d'énormes castagnettes en bois d'olivier, inconnues semble-t-il ailleurs, et sonores comme des cloches (cf. exemples $7 a$ et $7 b$ ).

Hors des provinces autrefois maures, les contrastes s'accentuent en effet. La guitare se fait rare et cède la place à d'autres instruments, avant d'être complètement supplantée par la cornemuse, reine du Nord. La

\footnotetext{
I A 3, 4, 6) ; Français : cf. CU 7 I (AIMP V A 1) ; Suisses : cf. MPS 1 (AIMP VII A 1-2).
} 
Catalogne, apparentée au domaine folklorique français, lui préfère les hautbois rustiques du type grallas $^{14}$ (cf. exemple 8).

Le Pays Basque, unité ethnographique particulière, aime surtout les flageolets, txistus, ${ }^{15}$ accompagnés de tambours (cf. exemple 9).

Dans les régions proprement espagnoles, de même, les chromatismes disparaissent, le chant long également, le rythme se raffermit. Témoin, ce chant de noce de Vieille-Castille (cf. exemple 10).

L'hypothèse de l'apparentement hispano-arabe se limite donc à l'Andalousie seule, et n'a pour tout soutien que le faux argument du chant richement orné ; mais celui-là même s'écroulerait si pareil chant devait réapparaître là où les Maures n'ont pu étendre leur conquête, aux Asturies par exemple ; et c'est précisément pourquoi nous nous dirigeons de ce côté-là. Voulant bien faire comprendre ce qui nous a attiré dans les Asturies, il nous a fallu préparer notre expédition vers cet antique refuge chrétien par une active randonnée en esprit à travers le reste de l'Espagne. ${ }^{16}$

Dans le réel, le voyage n'est pas rapide à l'excès non plus. Venant de France et passant la frontière dans la matinée, on sera acheminé sur voie étroite d'abord vers Bilbao, ensuite vers Santander par des trains de compagnies ferroviaires privées, en changeant de train, de gare et

14 Brailoiu prononce ici "grales", ou "grailes" ; mais il semble qu'il s'agit du hautbois catalan gralla(s), à six trous. Cf. P. José Antonio De Donostía et Juan Tomás (1947: 140-141 et 152, fig. 9).

15 Le txistu, ou chistu, appelé aussi txirola, txirula ou txulubita, est une flûte à bec proche du galoubet provençal, légèrement cônique et percée de trois trous. Les txistus sont toujours joués par groupe de trois : deux musiciens jouent d'un petit txistu d'environ $43 \mathrm{~cm}$. de long d'une main (dans la transcription musicale : txistus I et II), et s'accompagnent du tambour tamboril de l'autre ; le troisième joue d'une flute accordée une quinte plus bas, appelée silbote, qui nécessite l'usage des deux mains (cf. De Donostía et Tomás, $1947: 123,137)$.

16 Début de la seconde émission. 
de compagnie, pour n'arriver à Oviedo, au coeur des Asturies, que vers le soir. On traversera d'abord le Pays Basque, puis la Vieille-Castille, où le tracé de la ligne du chemin de fer longe une des régions accidentées dites montaña ; pays de vie pastorale annonçant les Asturies. Les bergers s'y interpellent dans les vallées, et si nous nous y arrêtions un instant, nous pourrions y avoir un avant-goût de la mélodie asturienne (cf. exemple 11).

Quelque chose de nouveau a résonné là, un accent que nous n'avons pas encore perçu ailleurs, qui fera infailliblement tressaillir tous ceux à qui la musique populaire asturienne est tant soit peu familière. Pour l'instant, il nous étonne, nous ne savons pas encore bien par quoi, mais assurément par l'émission ouverte, le timbre claironnant de la voix (cf. exemple 12).

Deux remarques, en passant, sur la ritournelle : primo, c'est une danse, jota ou fandango au choix, en tout cas l'une de ces danses à trois temps que maudissait Pierre Aubry dans sa charge contre l'Espagne de pacotille du café-concert. Les érudits sont maintenant d'avis que le fandango est relativement récent. Mais, récent ou ancien, il envahit petit à petit l'Espagne entière, non seulement celle des music-halls. En second lieu, l'instrument qui l'a joué était un flageolet, ${ }^{17}$ le Pays Basque reste proche, et la cornemuse ne règne pas encore seule comme plus loin. Plus loin, ce sont les Asturies, ancienne province d'Espagne, lit-on dans le Larousse, couverte par les Pyrénées asturiennes. Sur la carte, l'ancien royaume, principauté plus tard, affecte la forme approximative d'un triangle, couché le long de la côte, la base à l'ouest, vers la Corogne, la pointe à l'est, vers Santander. C'est une contrée verdoyante, que dominent partout les montagnes, dressées très près du rivage. Au couchant, derrière la petite ville de Luarca, s'étend un vaste territoire de pâturages habité par les fameux vaqueiros ("vachers"), ou ce qui en reste, population indépendante de pasteurs, propriétaires de leur bétail, vivant en marge des villageois sédentaires et plus ou moins tenus à l'écart par ceux-ci aux temps passés. Leur autorité suprême et

17 Il ne s'agit pas ici d'un instrument de type "flageolet" (flûte à bec), mais d'un hautbois, chirimía ou dulzaina. 
conseillère en toute chose est aujourd'hui, si elle vit encore, une vieille femme de l'Hospice catholique des vieillards à Luarca, âgée de plus de 90 ans, et nommée simplement Rugelia, ${ }^{18}$ laquelle, malgré son grand âge, va encore de temps à autre rendre visite à ses administrés spirituels dans la montagne, et secoue toujours son pandeiro avec une vigueur remarquable. Pandeiro, c'est-à-dire, par opposition au petit tambourin pandereto, le grand, seul instrument employé ici sauf la cornemuse, qui se fait quelquefois entendre près du rivage. Ni guitares, ni hautbois, ni flûtes d'aucune sorte. Le répertoire des vaqueiros consiste, à cette heure, essentiellement en danses vocales, rythmées par le pandeiro, donc certainement anciennes quant au genre. ${ }^{19}$ Mais l'obsédant fandango s'en est mêlé, et beaucoup sont à trois temps ${ }^{20}$ (cf. exemple $13^{21}$ ).

Souvent, une danse sert de refrain à un vieil air lyrique. En dépit de la liberté du rythme, le profil de ces airs-là, de plus en plus rares, reste sévère, quelque peu rude même, sans aucune propension à la virtuosité (cf. exemple 14).

Quant à la cornemuse, c'est un engin déjà standardisé, fabriqué par des artisans marchands, et généralement décoré de rubans et de franges

18 Cette informatrice se nomme Rogelia Gayo, dite "Rogelia la Vaqueira". Elle a été enregistrée dans les années 50 par Alan Lomax pour la BBC, ainsi que par D. Modesto Gonzalez Cobas, qui s’y réfère $(1975: 16)$.

Sans la nommer, Brailoiu fait ici allusion à la Vaqueirada.

20 Cette opinion de Brailoiu est contredite par celle de D. M. Gonzalez Cobas qui, après avoir réfuté avec raison le point de vue de $H$. Anglés, pour qui "les Vaqueiradas se distinguent des Asturianadas en ce qu'elles ne comportent aucun type de mélisme" (1954: 424), écrit : "Nous partageons par contre son critère selon lequel la Vaqueirada est construite sur des rythmes concrets, parmi lesquels ceux de forme ternaire abondent." (1975 : 56)

21 Les exemples musicaux 13 et 14 ont manifestement été intervertis dans l'émission de la RSR ; nous rétablissons donc dans nos transcripstions l'ordre des pièces tel qu'il avait dû être prévu par Brailoiu. 
bleus et rouges. Il a le privilège de se produire à l'église pendant la messe, notamment au moment de l'élévation ${ }^{22}$ (cf. exemple 15).

Il faut passer d'un bond par-dessus Oviedo, dans la partie Est du pays, pour nous rendre compte que nous venons de parcourir une sorte de sous-unité territoriale tout à fait distincte. C'est à l'autre bout des Asturies que nous connaîtrons leur musique populaire la plus typique. Là fleurit encore une vie paysanne exubérante, riche en cérémonies de toute espèce. On y vénère un grand nombre de Madones, et leur culte est l'occasion de grands pèlerinages, romerías, aux lieux de cette vénération. ${ }^{23} \mathrm{Ce}$ sont des festivités auxquelles participe tout un chacun, et qui durent parfois plusieurs jours. Certaines représentent visiblement dans leur état présent une fusion de rites divers, fondus en un ensemble organisé où se mêlent religieux et profane, chrétien et païen. ${ }^{24}$ On y porte d'habitude en cortège soit des statues saintes, soit quelque symbole immémorial, tel qu'un grand arbre ébranché jusque près du sommet, et que l'on plantera près de la chapelle où l'on va, soit plusieurs de ces petits arbres artificiels, chargés de pains rituels ou de fleurs, où point le souvenir d'un ancien culte des morts. Arbres et statues ont une escorte nombreuse de jeunes filles, qui revêtent, en ces seules occasions, le costume populaire, déjà tombé en désuétude. Elles tiennent toutes entre leurs mains un pandereto, qui leur sert à marquer la cadence de leur propre chant. On voit des tambourinaires de la Vierge qui n'ont pas encore atteint leur dixième année - et nous avons pu rencontrer

22 Cette pratique subsiste encore aujourd'hui. J'ai pu l'observer en août 1983 dans plusieurs villages de la région de Llanes (L.A.).

23 Si l'on se réfère à Gonzalez Cobas, l'origine des romerías serait liée à la Danza de los Romeros ("Danse des Pèlerins"), dans laquelle "les danseurs portaient la cape, le bourdon et la gourde", qui sont les attributs notamment, encore aujourd'hui, des pèlerins de Saint-Jacques de Compostelle. "Son origine doit se rattacher au temps des pèlerinages "à San Salvador de Oviedo" (1975: 18).

24 Plusieurs folkloristes et auteurs asturiens ont étudié la question de l'origine de ces coutumes selon le point de vue de la thèse celte, ou celto-ibère, notamment : N. Alvarez (1962), F. Carrera (1956) et J. Caso Gonzalez (1959). 
dans la bourgade de Llanes un ouvrier portant dans ses bras une Asturienne de quatre ans, armée d'un tambourin minuscule -; et ce qu'elles chantent, ce sont des cantiques pieux, tout au moins quant aux paroles. Les mélodies, au contraire, ne rappellent guère la liturgie. Très allantes et d'un rythme vif, elles semblent plutôt indiquer que les siècles ont imposé là un compromis entre l'antique tradition campagnarde et l'esprit de l'Eglise. Ecoutons quelques bribes, enregistrées avec un petit appareil portatif, aussi bien que faire se pouvait, et à franchement parler plutôt mal que bien. Leur authenticité totale fera oublier, espérons-le, l'imperfection du rendu acoustique (cf. exemple 16a).

Ces cantiques conservent leur forme de danse ou de marche, même lorsqu'il y est parlé de la Passion, des portes du Paradis et de la rédemption de l'homme (cf. exemple 16b).

Il est toujours fait une place, dans ces fêtes, à une façon de spectacle où se danse devant une assistance nombreuse et au son de la cornemuse le Pericote, presque un ballet, à coup sûr rituel jadis, mais dont la signification a été oubliée. ${ }^{25}$ Une rangée de filles y fait face à trois danseurs dont les mouvements sont chargés, au gré des ethnographes, d'un symbolisme compliqué, tout spécialement un de leurs gestes, qui consiste à lever le bras gauche et le plier à la hauteur du visage. L'aire de répartition du Pericote va jusqu'en Vieille-Castille. Tout s'achève par une danse de la population du village tout entière, la très célèbre

25 D'après F. Carrera, Le Pericote serait "antérieur à la christianisation de cette région - les Asturies. Le plus probable est qu'il soit celte : la cadence de sa musique, la similitude avec certaines danses gaéliques appuient cette hypothèse" (1956 : 304). L'origine du Pericote semble par ailleurs liée à celle du Corri-Corri, une danse de la région asturienne d'Arenas de Cabrales, qui a échappé à l'investigation de Brailoiu. Le symbolisme du Pericote serait de nature érotique, vitale et amoureuse, complémentaire à celui du CorriCorri, qui serait une danse de fécondité. Voir, à ce sujet, E. Pola Cuesta (1952 : 99) et García Matos (1979 : 27). 
Danza Prima, ${ }^{26}$ immense serpent humain qui avance lentement par les rues en faisant sans hâte trois pas en avant et un en arrière.

Alors même que l'on ignore ce que son nom signifie, la Danza Prima nous est décrite depuis le XVIIIe siècle par un Asturien, et nous en avons déjà fait mention sans la nommer parmi les ballades proprement dites, les récits dansés. Ce qu'on chante en dansant est en effet indubitablement narratif, bien qu'aujourd'hui fragmentaire. Les mélodies de tout cela, peut-être différentes d'ailleurs autrefois, n'ont plus rien de saillant aujourd'hui et ne prennent leur sens que jointes à leur chorégraphie, auquel cas leur enregistrement mécanique rencontre bien des obstacles. Toujours est-il que toutes ces choses, si intéressantes soient-elles, ne nous rapprochent guère de la solution du problème qui nous a conduit dans les Asturies, à savoir l'influence musicale arabe en Espagne. La réfutation de la thèse arabisante exigeait en effet un dernier argument : l'existence, en quelqu'endroit que les Maures n'ont pu atteindre, d'un chant aussi vocalisant que celui de l'Andalousie ; et ce chant, nous ne l'avons pas encore découvert. Par bonheur, il nous reste encore à prendre connaissance du suprême symbole musical des Asturies, de la musique la plus complètement représentative de l'endroit ; elle s'appelle, et c'est tout dire, l'Asturianada. ${ }^{27}$ Le mieux sera d'aller à sa rencontre sans préparation. Elle est encore si vivante en cette moitié occidentale du Principado que nous n'aurons pas besoin de la chercher beaucoup. Il suffira de pénétrer dans la première guinguette, où des jeunes filles s'abandonnent aux joies d'une conversation animée par des boissons liquoreuses, et nous verrons cette quintessence d'Asturiens dans toute sa fraîcheur ; vous voudrez bien excuser les interventions trop explosives des auditeurs (cf. exemple 17).

Le voilà enfin, en effet, ce chant orné que nous recherchions, mais plus orné encore - de beaucoup - que nous ne pouvions l'imaginer. Vous avez sans doute remarqué, outre certains coups de glotte retentissants - terreurs des micros - si caractéristiques du bel canto régional, le

Ibid. : 65-72. 
foisonnement des menus ornements et, aux fins de phrases, ces larges vocalises où la voix tourne longuement autour de la finale, comme battrait des ailes un oiseau avant de se poser. C'est un style traditionnel qui suppose une habileté consommée et que, néanmoins, tout homme et toute femme doués d'une bonne voix possèdent ; un style vocalisant encore vivace, au rebours de l'andalou, que seuls perpétuent des artistes pour le moins semi-professionnels. Mais ceci ne ressemble guère à cela. Il y a ici un mordant qui fait défaut en Andalousie et, de plus, les mélodies sont cette fois de construction rigoureusement régulière. ${ }^{28}$ Les plus fréquentes s'appuient sur une suite de cinq sons, tels que do, ré, $\mathrm{mi}, \mathrm{fa}$, sol, que l'ornementation déborde parfois légèrement au grave et à l'aigu (cf. exemple 18).

Les gens chantent si peu pour autrui dans ce coin de pays, qu'on peut y voir, les jours de fiesta, plusieurs chanteurs se cotiser pour engager à la journée un cornemusier, qu'ils auront sous la main dès que les travaillera le besoin de s'épancher en musique (cf. exemple 19).

Telle étant la situation aux confins de la Vieille-Castille, on n'en revient pas de se trouver autour d'Oviedo en présence d'une population "muette". L'Asturianada y a-t-elle disparu ? Non pas, mais elle n'y est plus à proprement parler présente. A force d'investigations, on finira par apprendre qu'il y a, à quarante kilomètres de là ou bien dans la rue voisine, un interprète incomparable ; et les stars en question, nous sera-t-il expliqué, s'ils ne donnent pas de concerts, ont cependant vu leurs mérites récompensés en des concours folkloriques publics, obtenant des diplômes et emportant chez eux des coupes de championnat. Leur métier importe peu, mais il n'y a pas de vrais paysans parmi eux : ils sont peintres en bâtiment, chauffeurs, miniers ${ }^{29}$ ou bonnes à tout faire.

En moins cristallisé, on retrouve là l'état de choses constaté en Andalousie, professionnalisation d'un répertoire présumé à l'origine

Ibid. : 75-83.

29

Brailoiu veut sans doute dire "mineurs". 
paysan là-bas, certainement paysan ici. C'est qu'Oviedo est situé à l'entrée de la "vallée à charbons", de cette cuenta minera que l'industrie a submergée presque du jour au lendemain. Une musique archaïque ardue, affaiblie par les conditions de vie nouvelles de la société, et désormais impraticable par le commun des mortels, s'est réfugiée auprès d'individus particulièrement doués, forcément dispersés. Conséquences : d'une part, une virtuosité accrue des exécutants exceptionnels, et d'autre part, une tendance progressive au concert et à la représentation devant un public. C'est pour cette dernière raison que des chanteuses, d'ailleurs brillantes, se font maintenant accompagner, à l'exemple des hommes, par la cornemuse (cf. exemple 20).

Il y aurait à ce propos un mot à dire des cornemusiers. Leurs préludes et interludes, abstraction faite des danses par lesquelles ils ont pris la mauvaise habitude de conclure, se nomment estribillos, ${ }^{30}$ et chaque bon instrumentiste en détient un petit assortiment ne dépassant pas la dizaine. L'estribillo est intéressant du point de vue de la musique espagnole savante ancienne, où l'on surprend certaines de leurs formules. Ajoutons en outre, concernant l'Asturianada elle-même, qu'elle ne se cantonne pas toujours dans la série do, ré, mi, fa, sol. Il arrive même que la mélodie embrasse une étendue considérable, tantôt descendant posément vers un point de repos, placé dirait-on à la limite inférieure extrême du registre vocal, tantôt s'élançant vers son extrême aigu (cf. exemple 21).

L'analyse n'est pas assez avancée encore pour que l'on puisse décider si pareils types sont aberrants par rapport à une norme, ou s'il s'agit d'individus mélodiques réguliers, simplement devenus rares. Tout ce qu'il est permis d'affirmer, c'est que presque toutes les chansons usuelles se meuvent entre do et sol. Il semblerait que les génies populaires s'évertuent à épuiser toutes les combinaisons de sons possibles entre ces deux jalons. Et comme le mouvement, très lent, ne varie guère, que le rythme se plie docilement au bon plaisir du chanteur, que l'émission

L'existence de l'estribillo ("refrain", "ritournelle") est en effet très ancienne dans le nord de la péninsule, également dans la musique "savante", comme l'attestent notamment les Cantigas de Santa María (XIIIe siècle). 
vocale, absolument spécifique aussi, demeure uniformément limpide, éclatante, ni gutturale, ni nasale, et constamment poussée à sa plus haute intensité, on a l'impression d'une perpétuelle répétition de la même mélodie, sans cesse variée. L'effet de cette fausse monotonie est puissant ; on dirait un lent engourdissement, un envoûtement, une manière de narcose, et cela aussi est à tel point particulier que, pour quiconque a séjourné là-bas, la moindre bouffée d'Asturianada évoque irrésistiblement les lieux où elle est née, ce dont rien ne rendra mieux compte que le chant magnifique que nous inclinons à tenir pour la perle $\mathrm{du}$ fonds asturien acquis jusqu'ici (cf. exemple 22).

Tel est, en quelques mots, le chant asturien. Il ne peut rien devoir aux Arabes dont l'expansion n'a pas atteint les Asturies. L'Andalousie, elle, les a connus, mais rien ne prouve qu'elle leur a emprunté sa musique.

Constantin Brailoiu 


\section{Commentaires des transcriptions}

La détermination des mélodies qui constituent les exemples s'est révélée particulièrement ardue, du fait de la rareté des informations s'y rapportant. Dans certains cas, la dénomination des pièces et des instruments n'a pu être établie que par recoupements et par comparaison avec d'autres enregistrements, notamment ceux réalisés par Manuel García Matos et édités dans sa Magna antología del folklore musical de España (1979). Par souci d'intelligibilité, nous avons fait suivre le titre générique et le lieu de collecte de chaque pièce de leur traduction française; faute d'un équivalent exact, une description lapidaire a été jugée suffisante. C'est ainsi que verdiales a été rendu par "air de fête", alborada par "ritournelle" - nous avons ici repris le terme utilisé par Brailoiu -, et que saeta et asturianada apparaissent tous deux comme "chants longs". Nous avons procédé de même pour le nom des instruments, en nous basant sur le vocabulaire typologique courant. Ainsi, par exemple, corneta est traduit par "clairon", sans autre commentaire ; mais nous indiquons pour bandurria : "mandore, petit luth à fond plat", et pour grallas : "hautbois catalans". L'orthographe de noms comme donsaina, txistu ou pandeiro variant d'une région d'Espagne à l'autre, d'une langue ou d'un dialecte à l'autre, nous avons adopté celle correspondant au lieu où l'enregistrement a été réalisé. Finalement, chaque fois qu'apparaît la cornemuse (gaita), figurent les termes de cantante : "chanter",1 et de bordón : "bourdon", qui définissent les deux tuyaux de l'instrument.

La diversité du matériel enregistré a posé un certain nombre de problèmes de transcription, autant sur le plan mélodique que sur celui du rythme. La hauteur absolue des sons indiqués correspond autant que possible à celle mesurée sur les bandes qui nous ont été fournies. Une pièce comme celle de l'exemple 11 s'est révélée être un véritable casse-tête, car la ligne mélodique de ses différentes parties n'a rien à voir avec le cadre tonal commun aux autres exemples musicaux; il a donc fallu adopter là une restitution approximative n'ayant d'autre prétention que de montrer son contour mélodique. Pour ce qui concerne l'armature et les altérations d'une manière générale, les transcriptions $4,5,6,7,8,11,13,14,17$ et 21 n'étant manifestement pas réductibles au tempérament égal, nous avons choisi les signes $\dot{b}$ et $\$$ pour noter les tons intermédiaires; mi b̆correspond ainsi à un son situé entre mi bet mi, et fa entre fa et fa ornementaux sont rendus par des notes plus petites que les autres. Une ligne horizontale suivant une note signifie que celle-ci est tenue; lorsque la ligne est sinueuse, c'est que la tenue est affectée d' une oscillation microtonale ou d'un trille, ce dernier étant précédé du signe tr.

1 "Chanter" : nom breton du petit hautbois qui produit la mélodie de la cornemuse; le mot est aussi utilisé dans la langue française. 
Ces exemples musicaux font par ailleurs état d'une grande disparité rythmique, laquelle a nécessité l'adoption de plusieurs types de transcription :

Les "chants longs" - exemples 4(B), 5(B"), 10(D), 11, 12 (derniers $A A$ ' $B), 14(A)$, et 15 à 22 inc. -, au rythme libre, non mesuré, ont bien sûr été transcrits sans barres de mesure et les notes y sont dépourvues de queue.

Dans la pièce 1, les rapports de durée sont mesurables mais font apparaître une pulsation rythmique variant du binaire au ternaire, voire au quinquenaire, irréductible à un mètre itératif. La solution des demi-barres de mesure permet de signaler cette pulsation sans enfermer l'air dans une métrique étrangère à sa logique propre.

Tout le reste est mesuré, parfois d'une manière claire et évidente -exemples $2,3,6,7 b, 8,9,10(A B C), 12$ (premiers $A B), 13,14(B$ à $E), 16 a$ et $16 b$ -, parfois par le seul battement de tambours - exemples $4(A), 7 a-$, ou même par une pulsation sous-entendue -exemple 5(ABB'A [...] A) -, mais la mélodie y évolue librement.

Dans tous ces cas, une restitution rythmique conventionnelle a été adoptée.

La plupart des morceaux sont subdivisés en sections, distinguées par des lettres majuscules. Quant la ou les reprises d'une section sont identiques à leur exposition, elles sont mentionnées par la répétition de la lettre $(A A)$; lorsqu'elles comportent des variations mélodiques ou rythmiques, la présence de ces dernières est indiquée par les signes ', ", etc. (AA'A"...). Dans certains cas (exemples 2, 10, 12), la structure globale de la pièce ne transparaît pas à la lecture, de façon à ne pas la surcharger d'inutiles répétitions; elle a donc été signalée en sous-titre. Les parties purement instrumentales y figurent entre parenthèses, pour qu'elles ne soient pas confondues avec celles qui sont chantées.

Bien que la grande majorité de ce matériel soit vocal, il n'a malheureusement pas été possible d'en reproduire les paroles. Brailoiu ne les avait pas notées, et les spécialistes auxquels nous avons fait appel n'ont pu les établir avec certitude; nous avons donc renoncé à en livrer les fragments compréhensibles, trop rares et incomplets. Un aspect important de ce répertoire semble bien perdu, et c'est d'autant plus regrettable qu'il aurait permis de se faire une idée de la quantité insoupçonnée de dialectes existant en Espagne au sein des quatre groupes linguistiques que sont le castillan, le catalan, le galaico-portugais et le basque.

Laurent Aubert 
ALVAREZ, N.

\section{RÉFÉRENCES}

1962 : Origen, proyecciones y enlaces de la música popular asturiana. Oviedo : Bidea.

ANGLES, $\mathrm{H}$.

1964 : "Relations of Spanish Folk Song to the Gregorian Chant", Yearbook of the International Folk Music Council, XVI, 54-56.

ANGLES, H. et PENA, J.

1954 : Diccionario de la música. Barcelone : Labor.

AUBERT, L.

1985 : "La quête de l'intemporel. Constantin Brailoiu et les Archives internationales de musique populaire", Bulletin du Musée d'ethnographie (Genève), 1985/27, 39-64.

AUBRY, P.

1907-08 : "Iter Hispanicum : Las Cantigas de Santa María", Sammelbände der internationalen Musikgesellschaft, IX, 32-51.

BRAILOIU, C.

1960 : Vie musicale d'un village. Recherches sur le répertoire de Dragus (Roumanie). Paris : Institut universitaire roumain Charles ler.

1973 : Problèmes d'ethnomusicologie. Textes réunis et préfacés par G. Rouget. Genève : Minkoff Reprint.

CARRERA, F.

1956 : Algo sobre las tradiciones populares en el oriente de Asturias. Oviedo : Bidea.

CASO GONZALEZ, J.

1959 : El celtismo de la canción tradicional asturiana. Oviedo : Bidea.

CHOTTIN, A.

1938 : Tableau de la musique marocaine. Paris : Geuthner.

DONOSTÍA, J. A. de et TOMÁS, J.

1947 : "Instrumentos de música popular española. Terminología general. Ensayo de clasificación", Anuario musical (Barcelone), II, 105-152.

FARMER, H. G.

1929 : History of Arabian Music in the Thirteenth Century. Londres : Luzac \& Co.

1930 : Historical Facts for the Arabian Musical Influence. Londres : Luzac \& Co. 
GARCÍA MATOS, M.

1950 : "Cante flamenco. Algunos de sus presuntos orígenes", Anuario musical (Barcelone), V, 97-124.

1951 : Cancionero popular de la provincia de Madrid. Ed. critique par M. Schneider et J. Romeu Figueras. Barcelone-Madrid : C. S. I. C.

1954 : "Instrumentos musicales folklóricos de España. I. Las xeremies de la Isla de Ibiza", Anuario musical (Barcelone), IX, 161-178.

1956 : "Instrumentos musicales folklóricos de España. II. La gaita de la sierra de Madrid. III. La alboka vasca", Anuario musical (Barcelone), XI, 123-163.

GARCÍA MATOS, María C.

1979 : "Especies musicales folklóricas del pueblo español en su ciclo vital", in M. García Matos (réalisateur) : Magna antología del folklore musical de España (coffret de 17 disques $33 \mathrm{t} .30 \mathrm{~cm}$. avec plaquette), p. 15-35.

GONZALEZ COBAS, $M$.

1975 : De musicología asturiana. La canción tradicional. Oviedo : Instituto de estudios asturianos.

GÜNTHER, R.

1969 : "Special Bibliography : Marius Schneider", Ethnomusicology, XIII/3, 518-526.

KATZ, I. J.

1974 : "The Traditional Music of Spain : Explorations and Perspectives", Yearbook of the International Folk Music Council, XVI, 64-85.

LARREA, A. de

1949 : "La saeta", Anuario musical (Barcelone), IV, 105-135.

1978 : “Arab Music in Spain”, Second Baghdad International Music Conference. Baghdad : Iraqi National Music Committee (ronéotypé).

NATTIEZ, J. J.

1984 : Brailoiu, collecteur, comparatiste et structuraliste. Contribution à l'histoire de l'ethnomusicologie. Genève : Archives internationales de musique populaire.

POLA CUESTA, E.

1952: El Pericote. Oviedo : Bidea.

RIBERA Y TARRAGO, J.

1922 : La música de las cantigas : Estudio sobre su origen y naturaleza. Madrid.

1927 : Historia de la música árabe medieval y su influencia en la española. Madrid. 


\section{SCHNEIDER, $M$.}

1946a : "A propósito del influjo árabe. Ensayo de etnografía musical de la España medieval”, Anuario musical (Barcelone), I, 31-141.

1946b : El origen musical de los animales-símbolos en la mitología y la escultura antiguas. Barcelone : Instituto español de musicología.

1948 : La danza de espadas y la tarantela. Barcelone : Instituto español de musicología.

1949 : "Los cantos de lluvia en España", Anuario musical (Barcelone), IV. 
Voix de femme
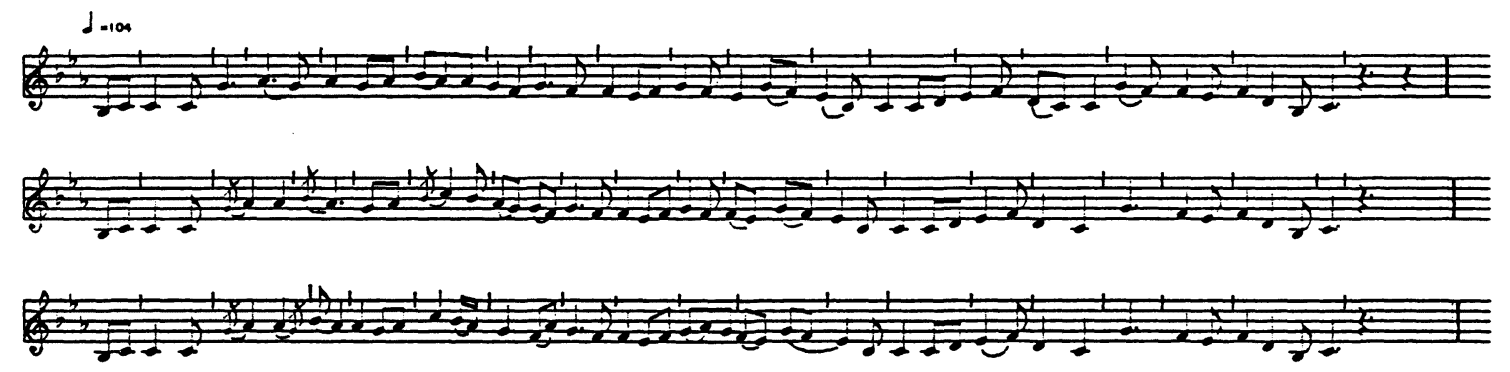

Exemples dans cet article produit par MusPrint $3.4^{\circledR}$ Keith A. Hamel, 1986. 


\section{Verdiales, Málaga}

(Air de fête, Malaga)

(AA)AABAAB(AA)
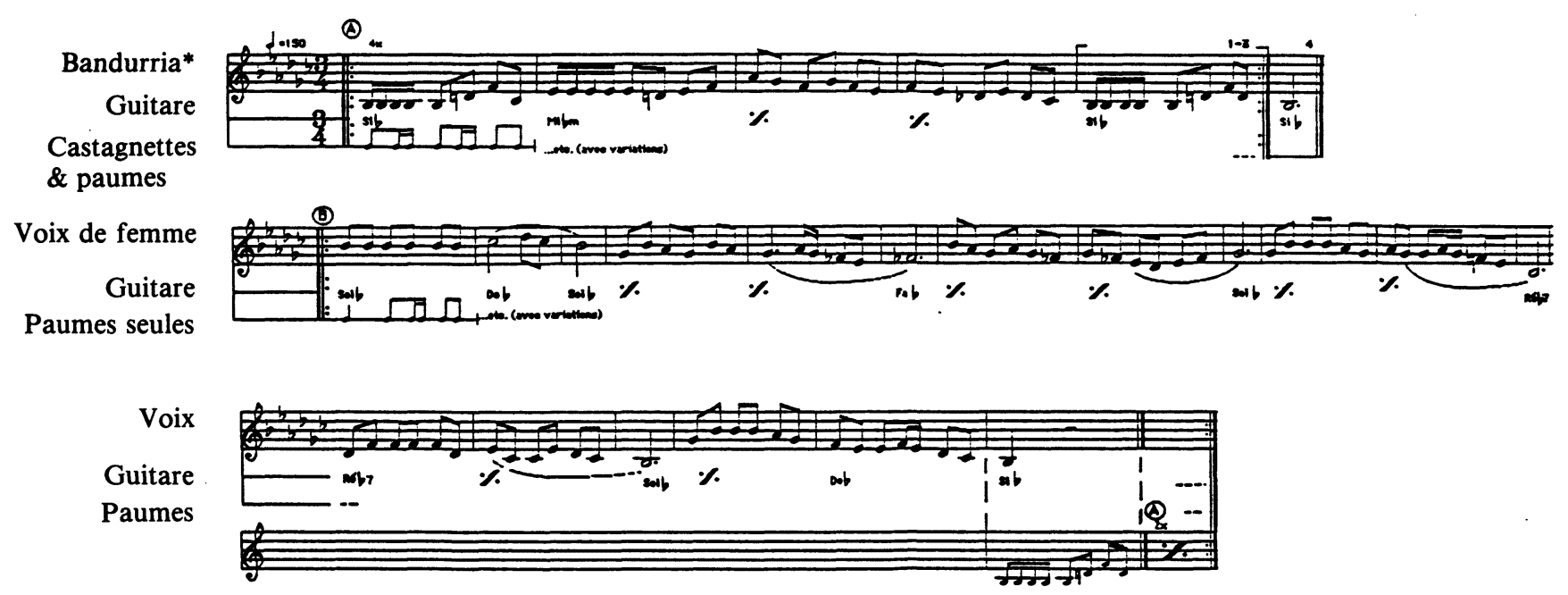

*Mandore, petit luth à fond plat

Bandurria

\&

Castagnettes

జิ 
훙

\section{Voix de femmes \\ Pandereta*}

Castagnettes

(seulement 2, 3, 5, 6)

\section{$\mathrm{VX}$}

*Tambourin, tambour-sur-cadre à cymbalettes

(Danse chantée, Salamanque)

3. Bolero, Salamanca

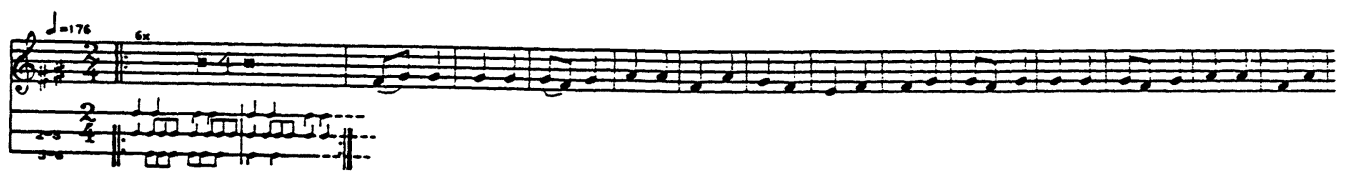




\section{Saeta, Sevilla}

("Chant long", Séville)

d)

Corneta*

Tambor**

27

211

$21+1+1\}+\cdots$

(3)

Voix d'homme
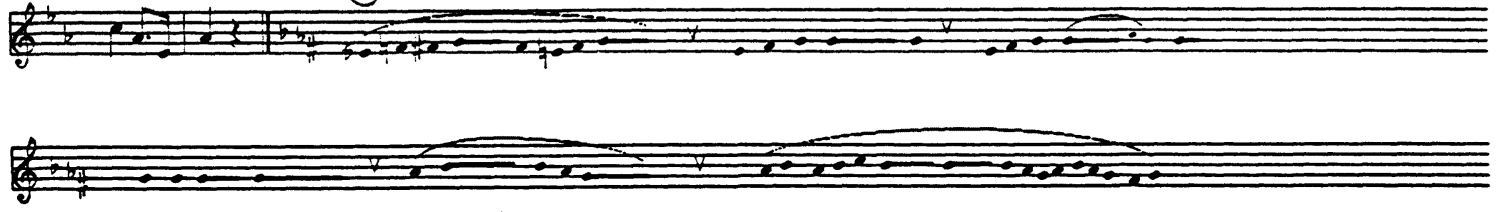

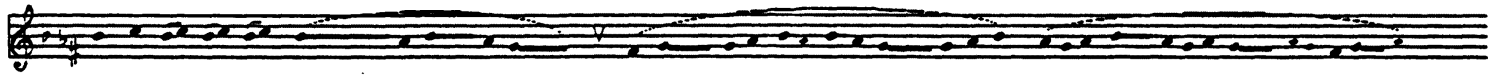
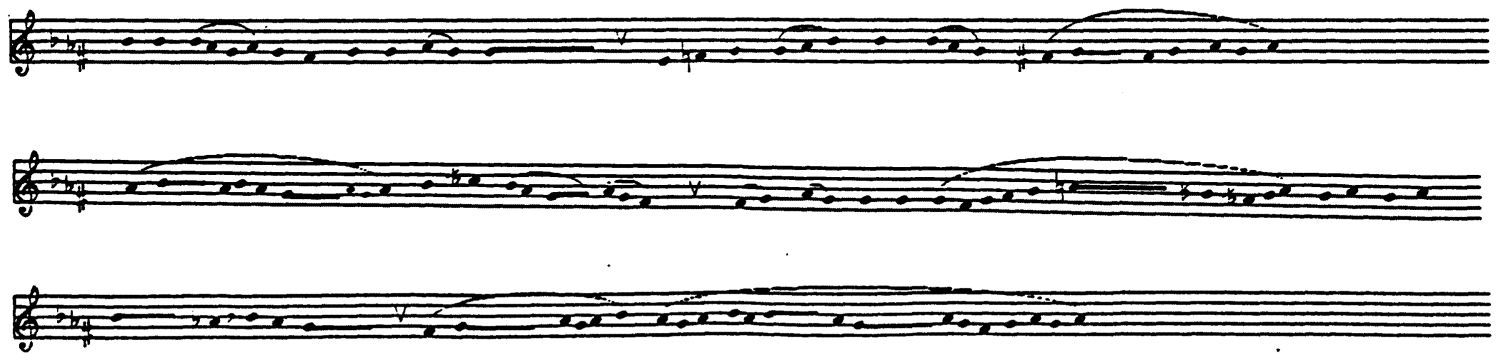

究

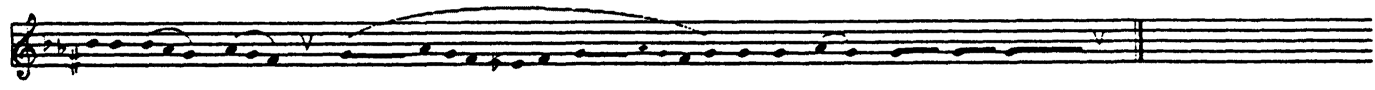

*Clairon

**Tambour 


\section{Alba, Valencia}

(Aubade, Valence)

d. $=130$ (A)

Donsaina*

(7) $\mathrm{rat}$

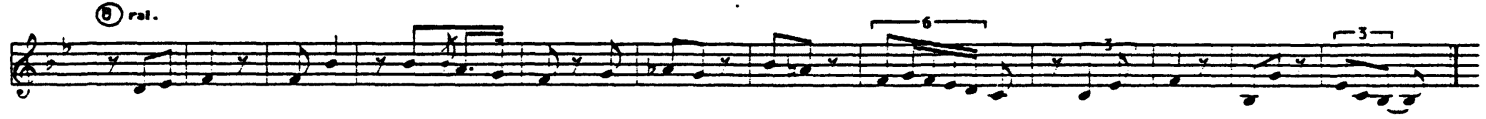

(․)
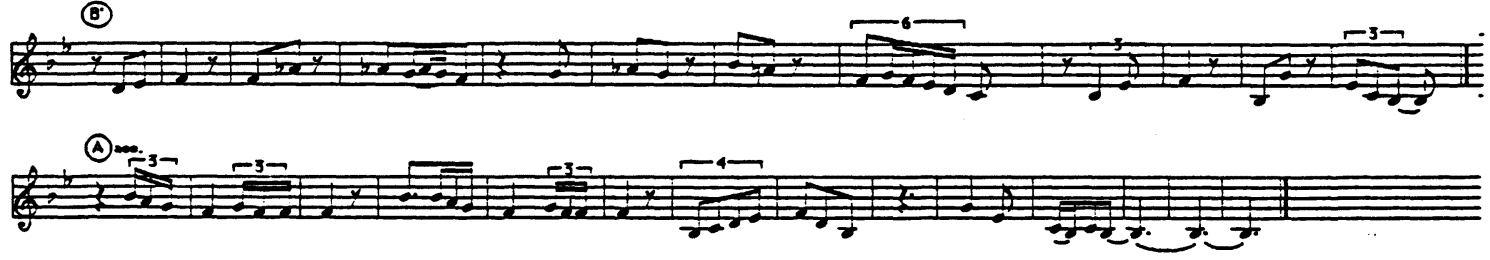

(ా)

Voix de femme I

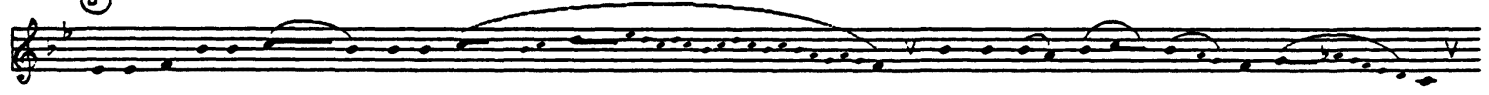

(-) Voix de femme II
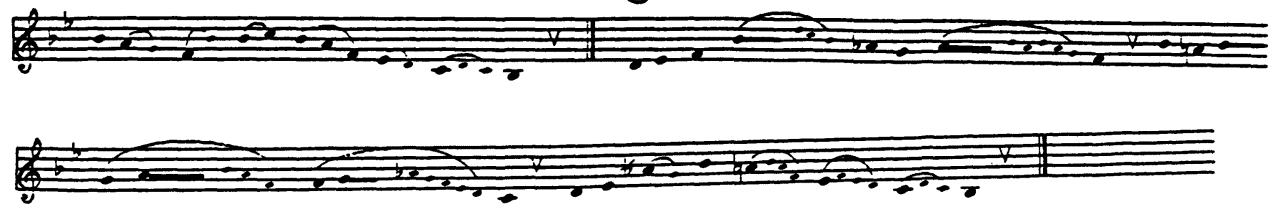

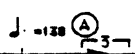

Donsaina

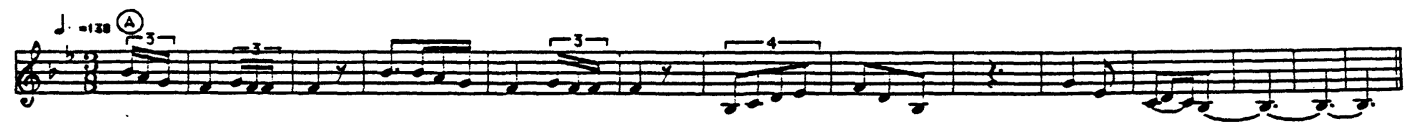

*Douçaine, hautbois de Valence 


\section{Canción navideña, Ibiza} (Noël, Ibiza)
*Flûte à bec de Catalogne et des Baléares

**Petits tambours de Catalogne et des Baléares

Voix d'hommes

Flaviol*

$$
\text { d } 190
$$

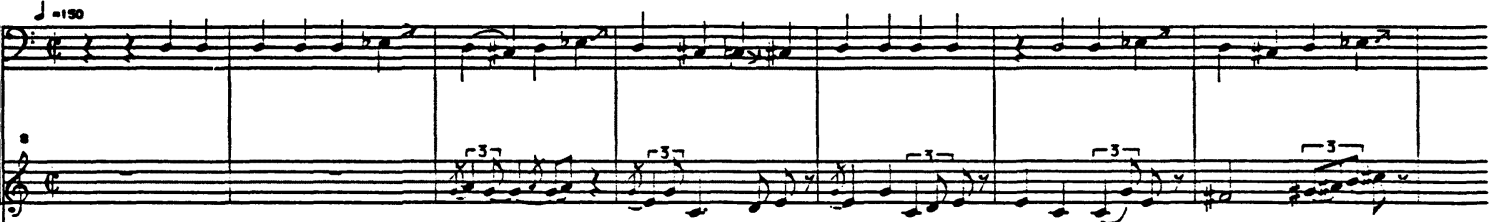

Tamborets**

a.

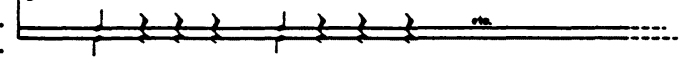

Vx

Fl.

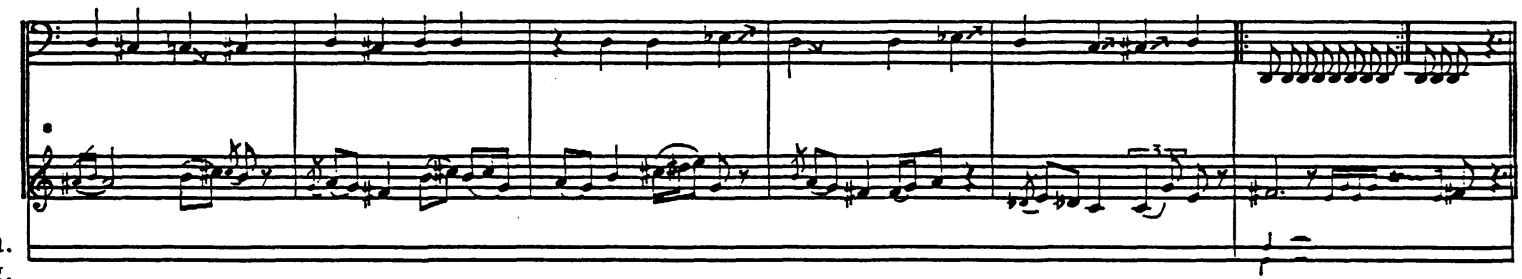

Fl.

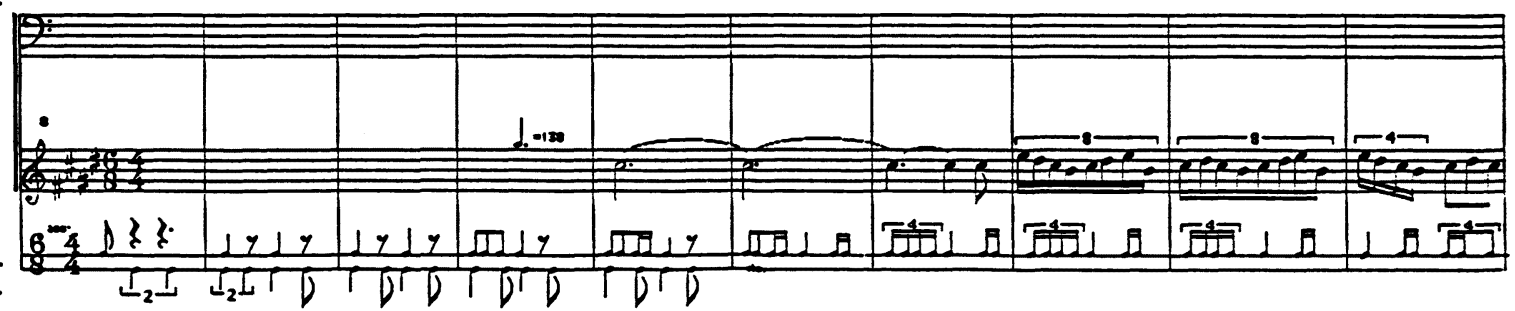


홍

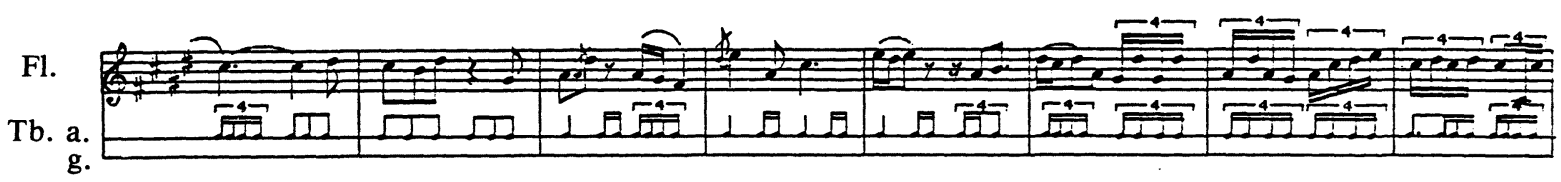

Fl. $\mathrm{T}$. $\mathrm{g}$.

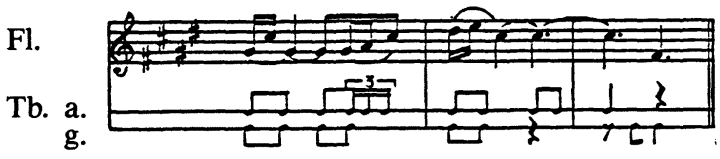


7a. Cobla ibicenca, Ibiza

(Danse, Ibiza)

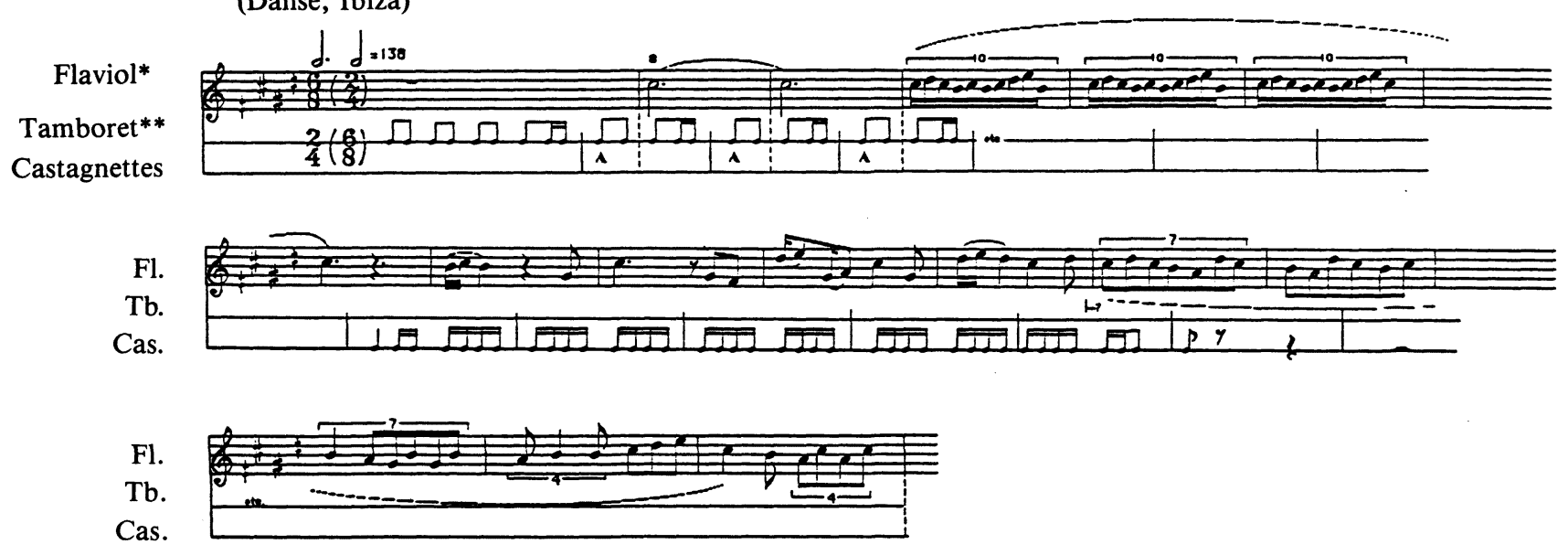

*Flûte à bec

**Petit tambour 
7b. Cobla ibicenca, Ibiza

(Danse, Ibiza)
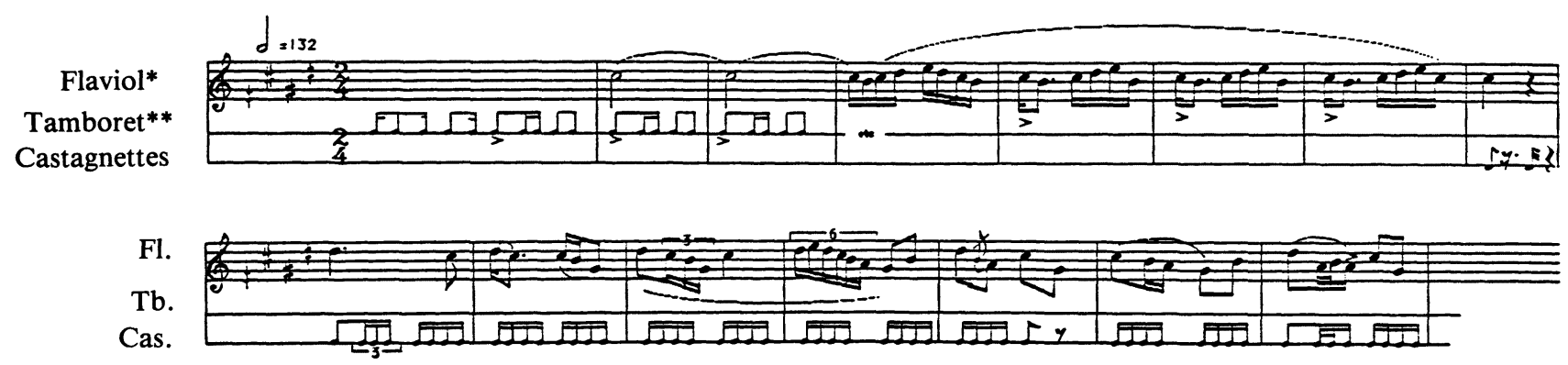

Fl.

Tb. *Flûte à bec

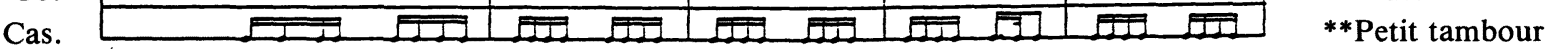




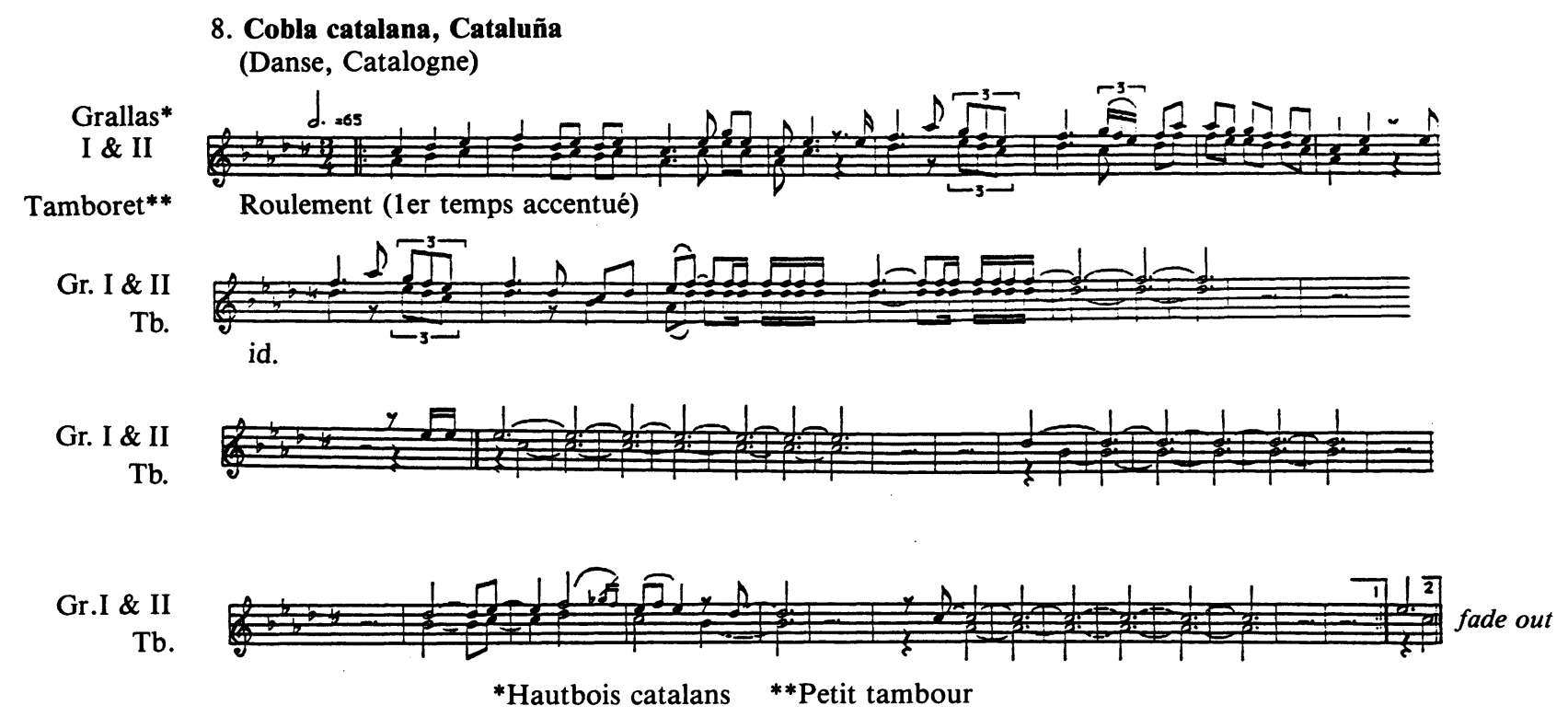




\section{Banda de Txistularis, País Vasco}

(Gaboulets et tambours, Pays Basque)

AA'BB'CCDAB'

Txistu* I

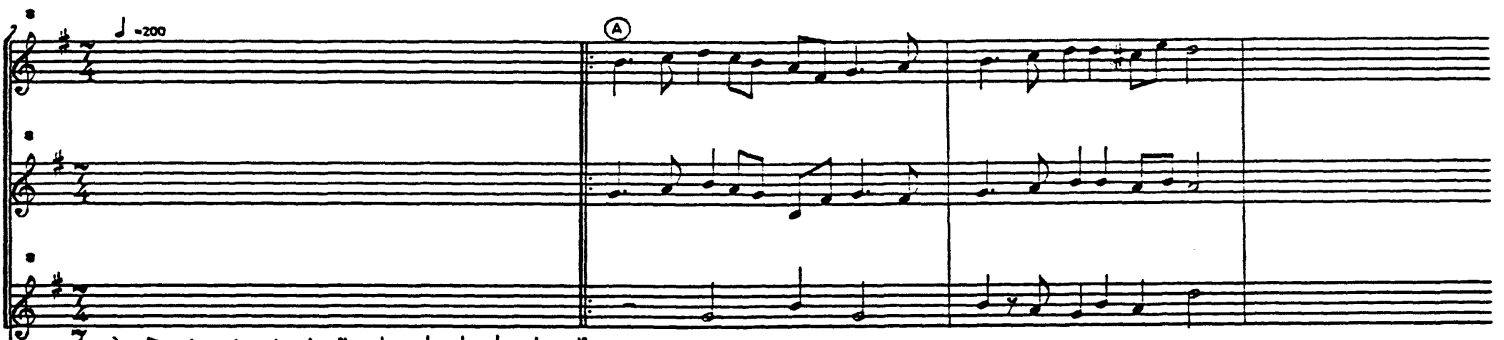

Tamboriles***

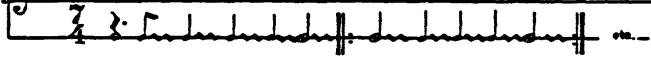

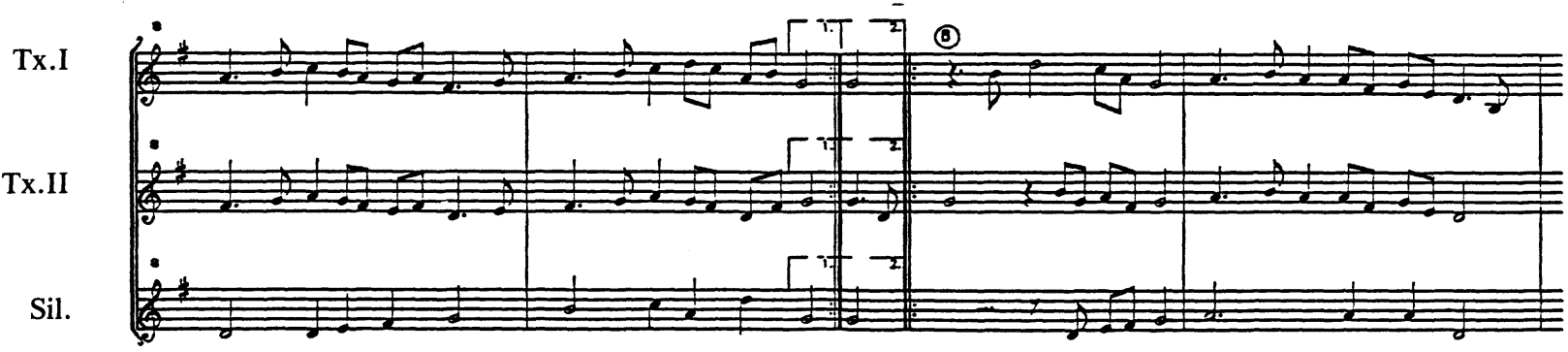

Tx.I

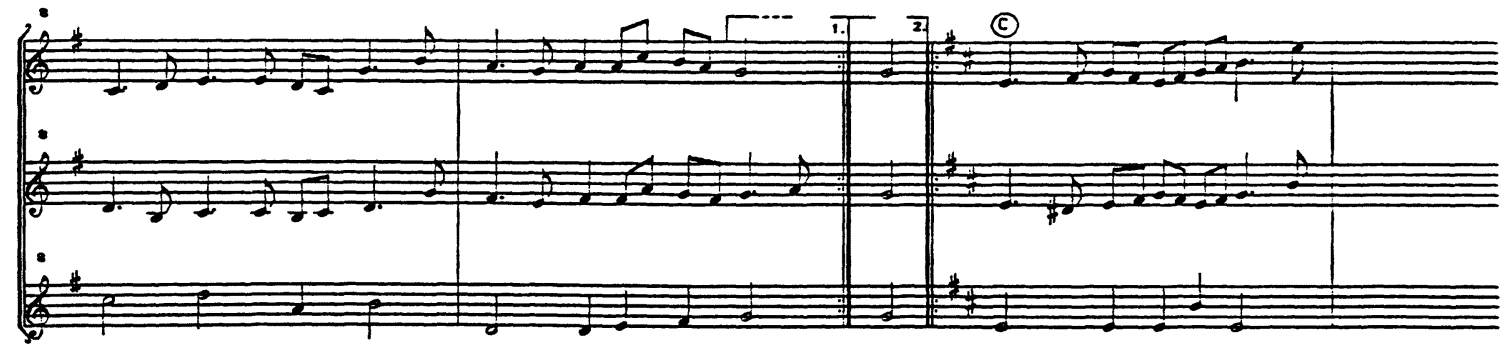



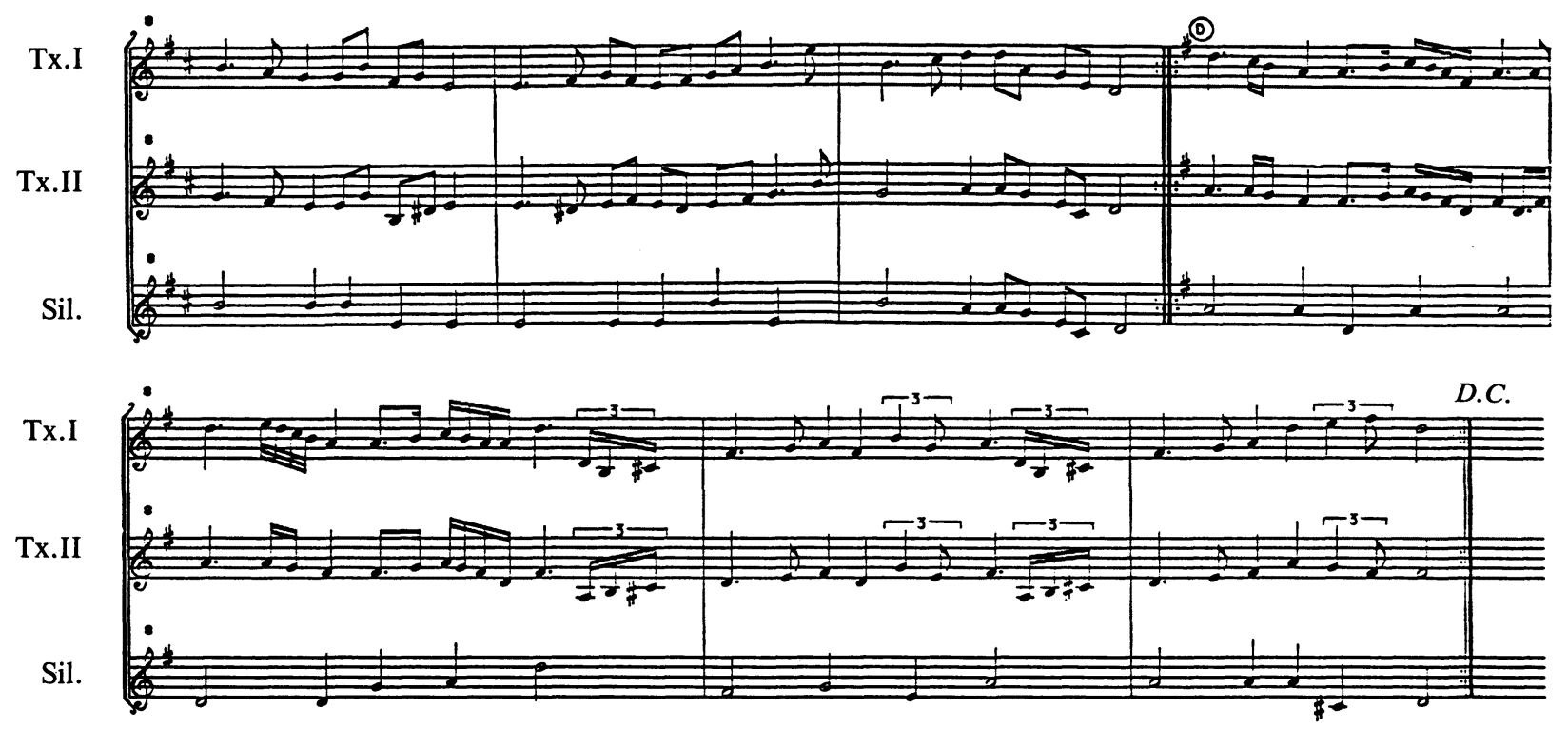

*Gaboulet, flûte à bec basque

**Gaboulet basse (se dit aussi txistu aundia) $\quad$ ***Petits tambours basques 
(Chant de noce, Vieille-Castille)

(AABB'CB")D(CB")

Chirimía*

」.210

(4)

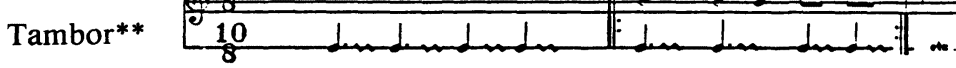

Ch.
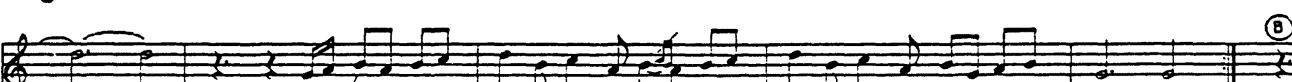

(B)

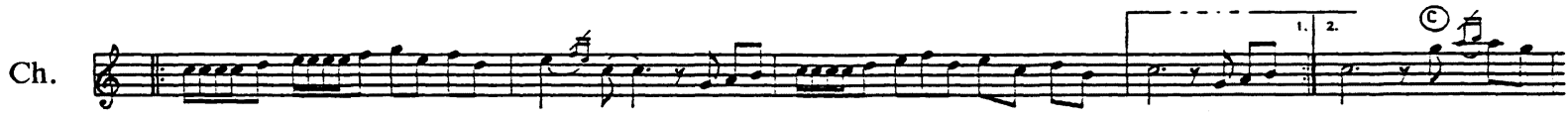

Ch.

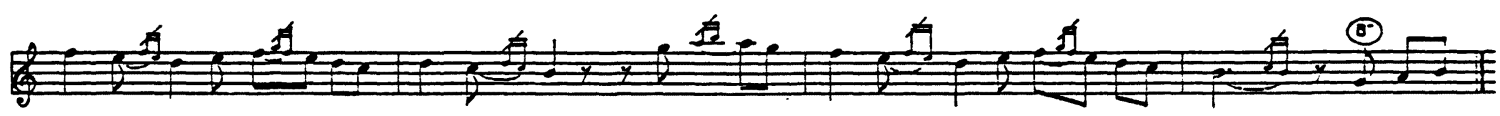

Ch.

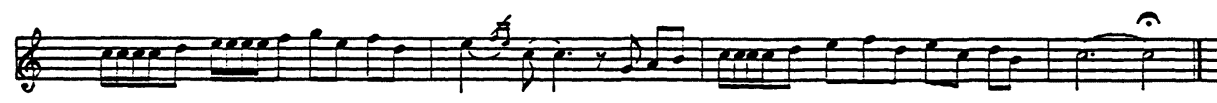

Voix de femme<smiles>C1#CC#C1</smiles>

(2) 

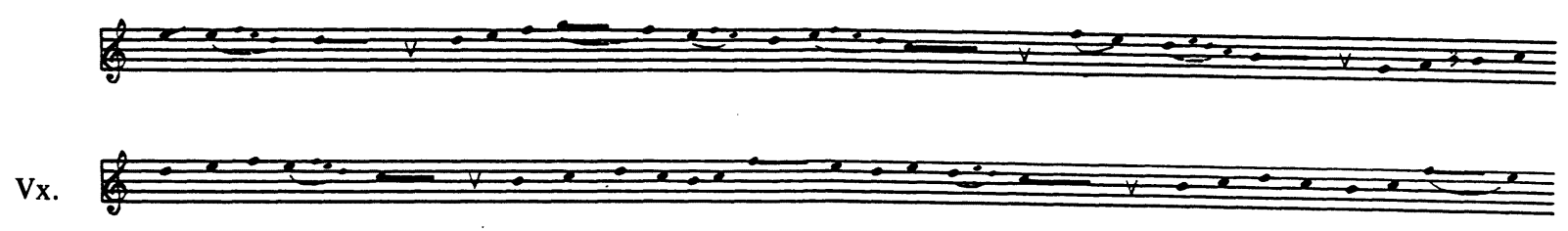

Vx. Chirimia \& tambor C $\mathrm{C}$ "

*Chalemie, hautbois

**Tambour 
초

Voix d'homme,

Berger I

Voix d'homme, Berger II

11. Llamamiento de pastores, Castilla la Vieja

(Appel de bergers, Vieille-Castille)

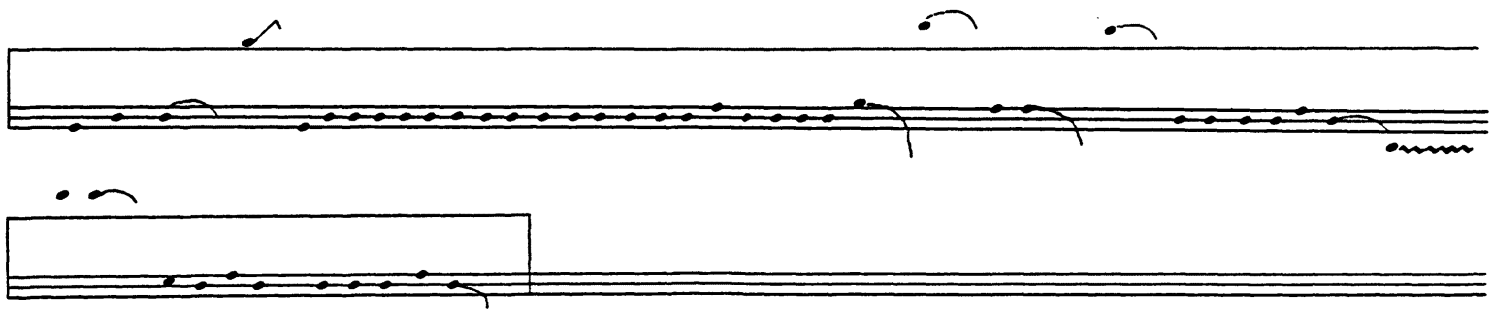

B.II

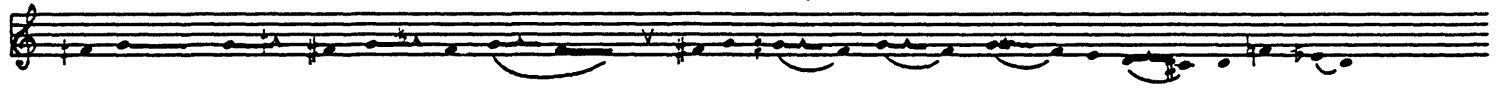

B.II

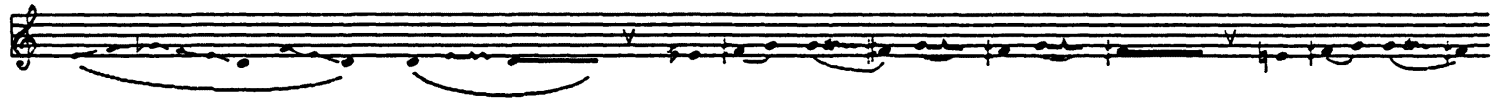

B.II<smiles>[Te]=[Te]</smiles>

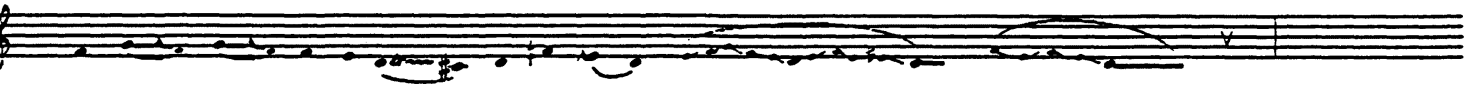




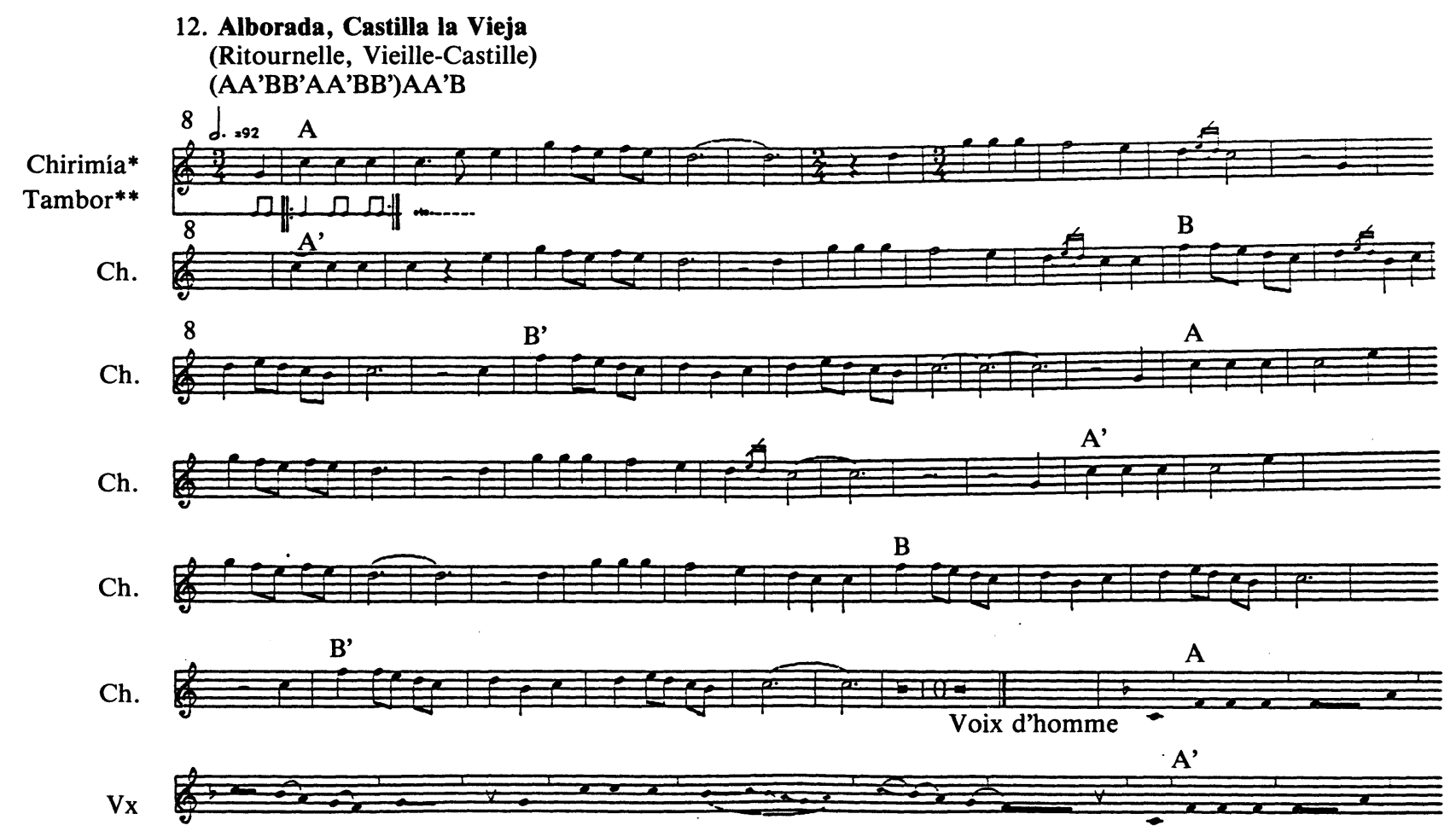


$\bar{\varpi}$

VX.

$\mathrm{Vx}$

$\mathrm{Vx}$ 
13. Vaqueirada, Asturias, región de Luarca

(Chant de vacher, Asturies, région de Luarca)

Voix d'homme
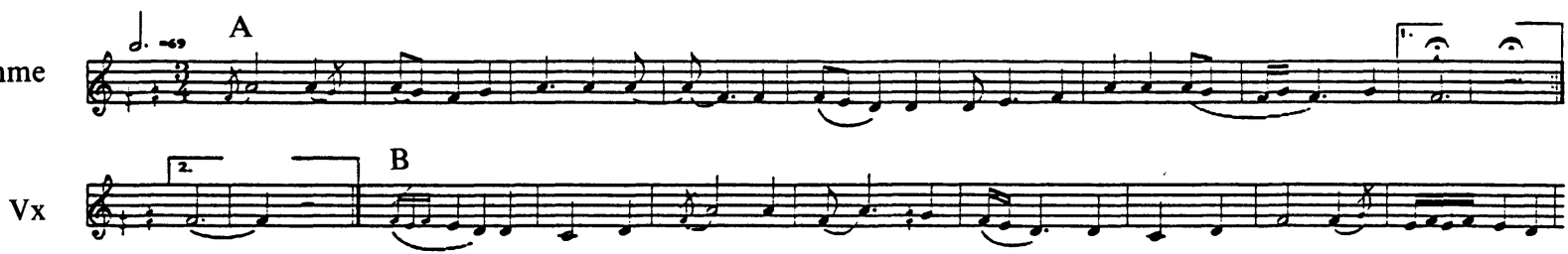

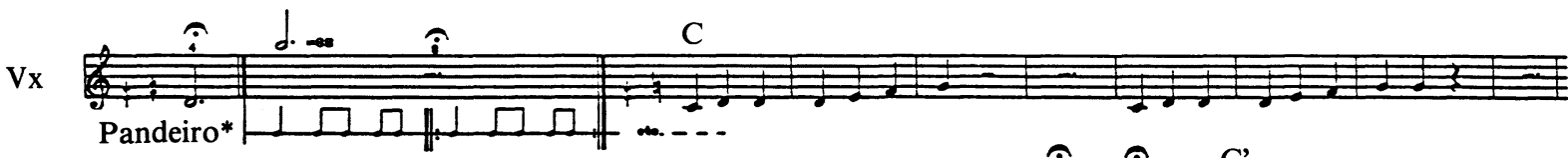

Vx

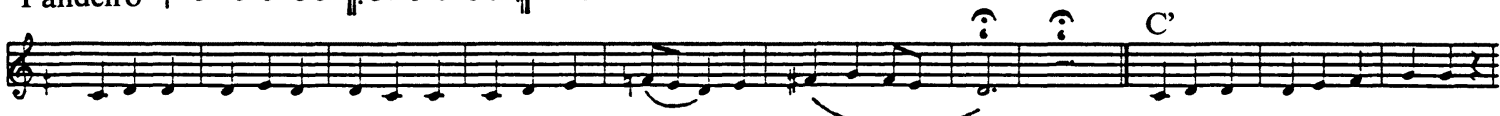

$\mathbf{V x}$

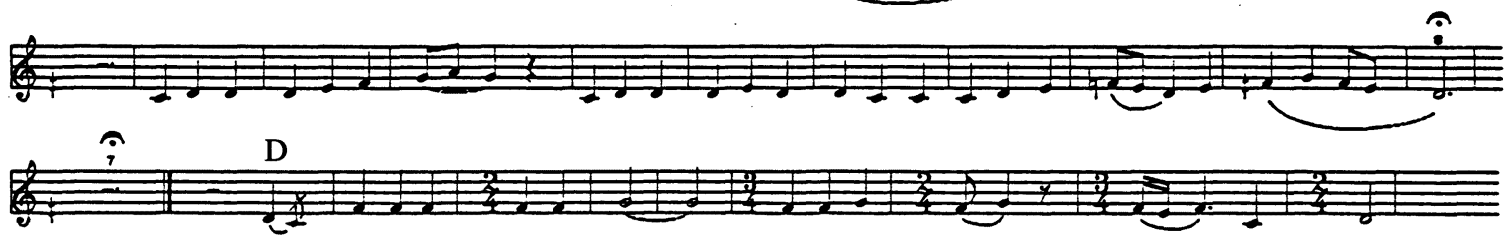

$\mathrm{Vx}$

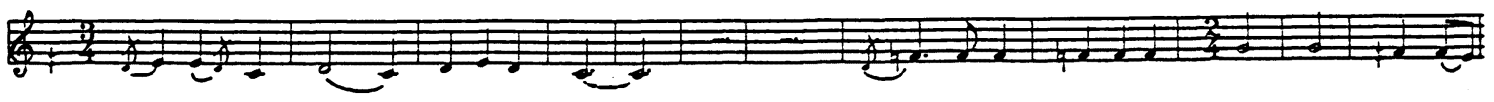


홍
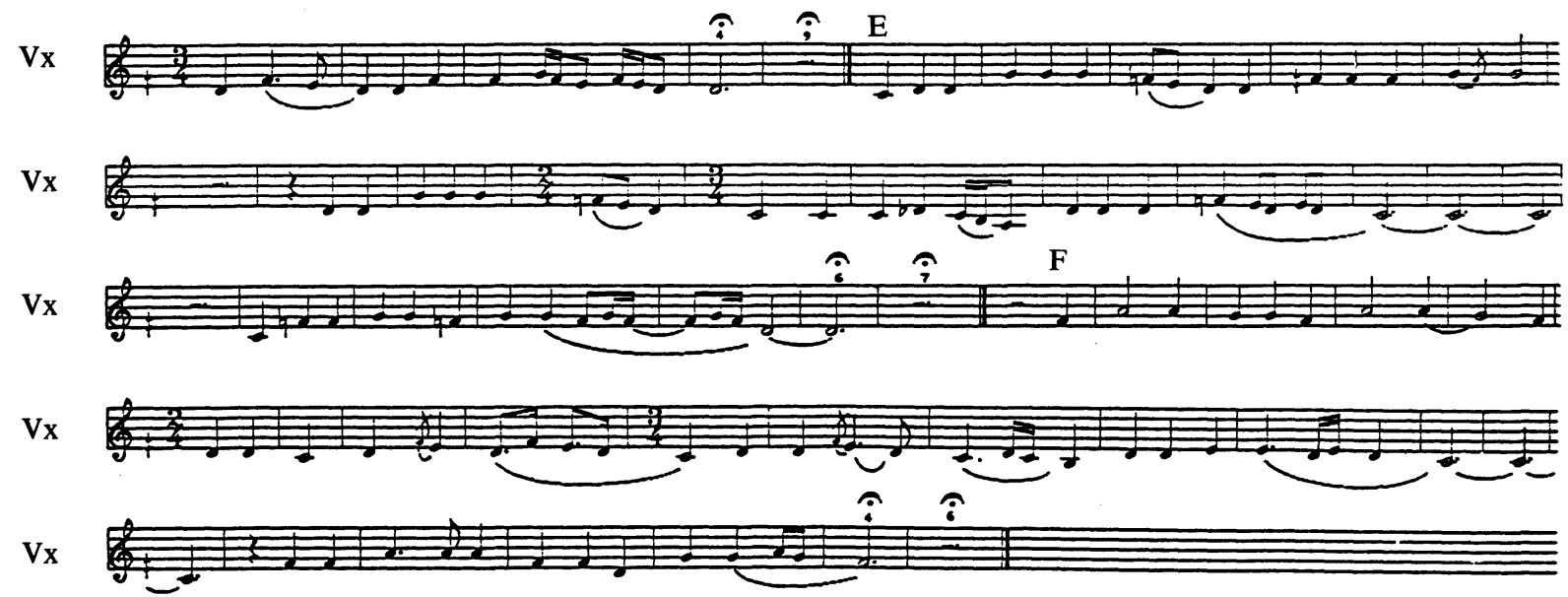

*Tambour-sur-cadre 


\section{Vaqueirada, Asturias, región de Luarca}

(Chant de vacher, Asturies, région de Luarca)

ABB'CDEE'

Voix d'homme
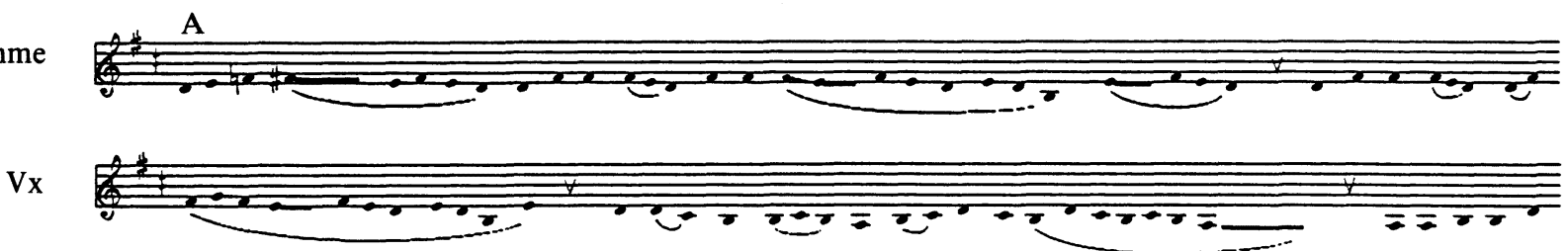

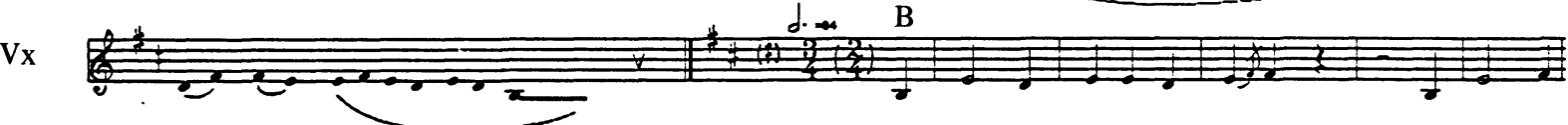

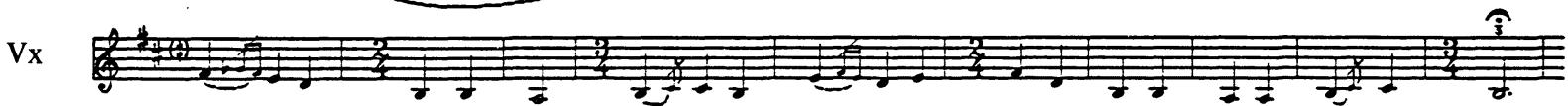

B'

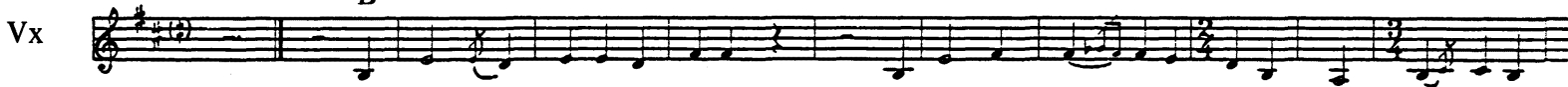
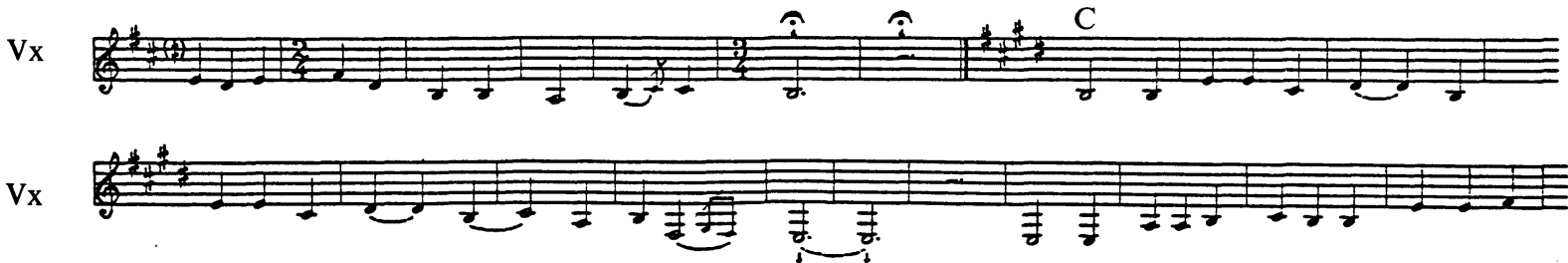
우

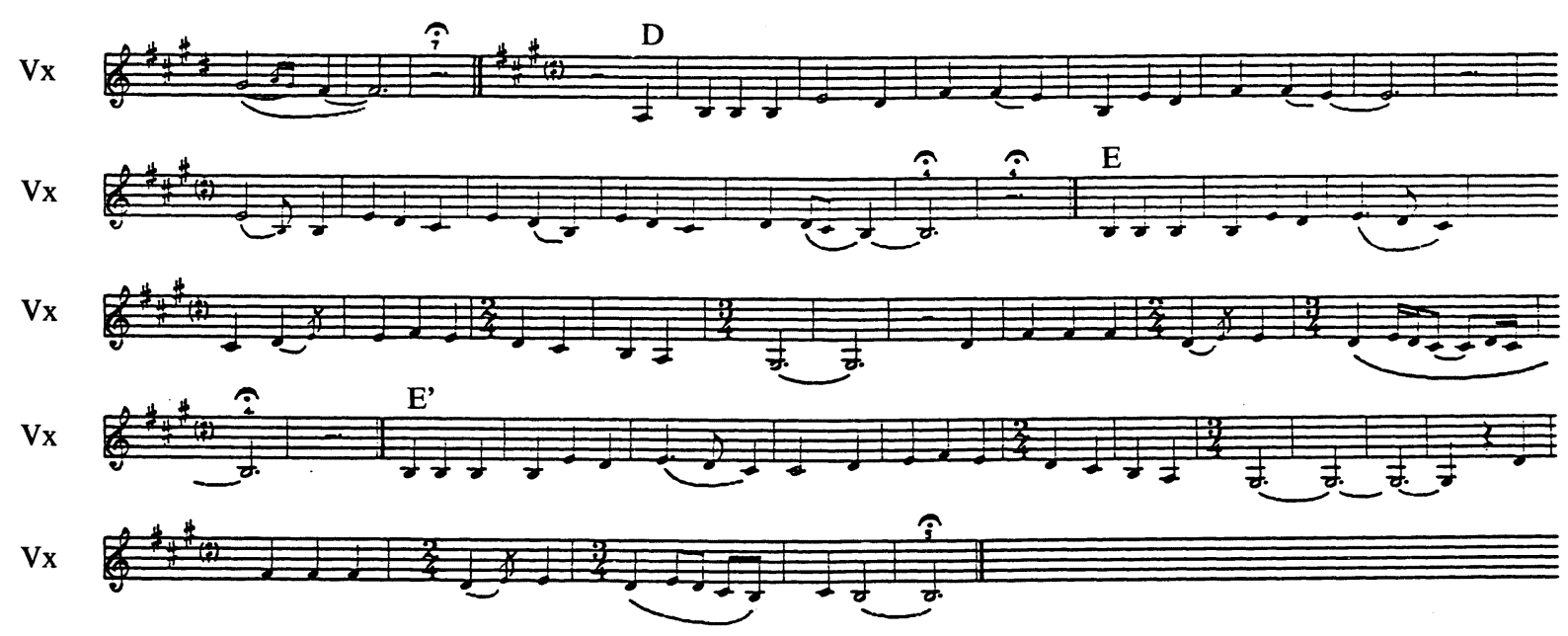


15. Toque de gaita, Asturias, región de Luarca

(Sonnerie de cornemuse, Asturies, région de Luarca)

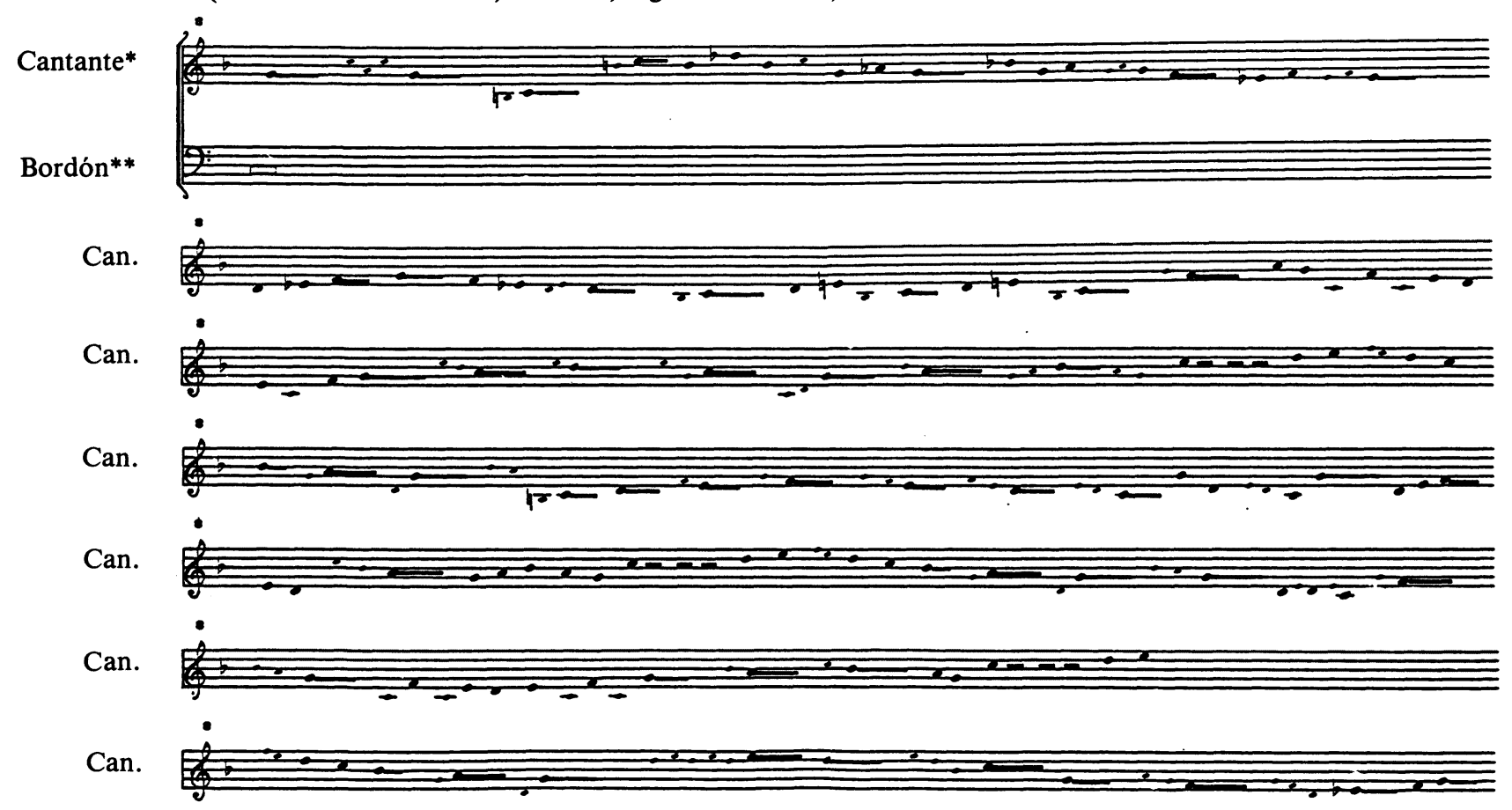

*Chanter, hautbois mélodique de la gaita (cornemuse)

**Bourdon 
16a. Canto de romería, Asturias, región de Llanes

(Chant de pèlerinage, Asturies, région de Llanes)

Voix de fillettes

Panderetas*

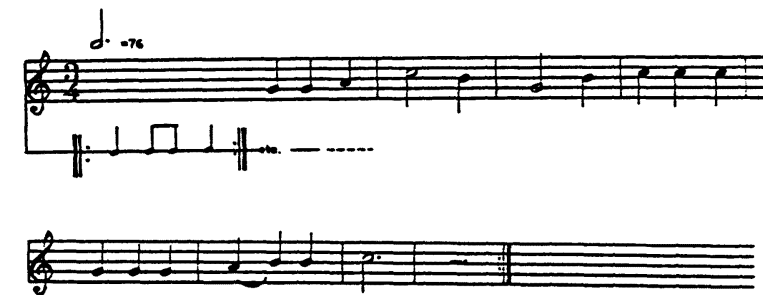

*Tambourins, tambours-sur-cadre à cymbalettes

16b. Canto de romería, Asturias, región de Llanes

(Chant de pèlerinage, Asturies, région de Llanes)

AAA'B / AAA'B

Voix de fillettes

Panderetas*

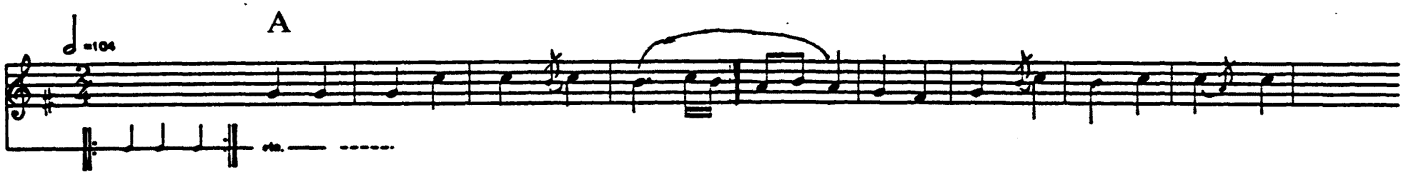

A

$\mathbf{V x}$

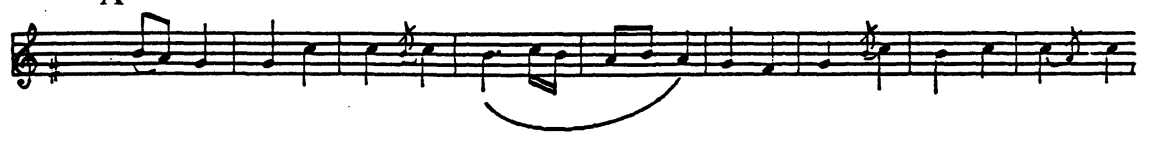

\section{$A^{\prime}$ B}

Vx

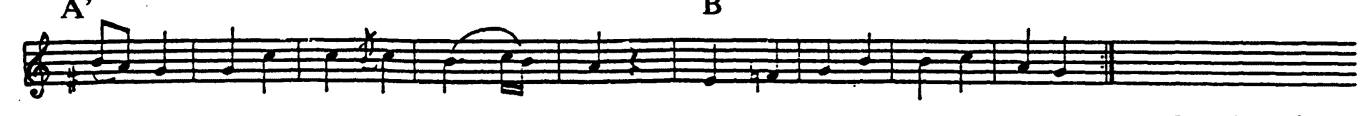

*Tambourins 
17. Asturianada, Asturias, región de Llanes

("Chant long", Asturies, région de Llanes)

Voix d'homme
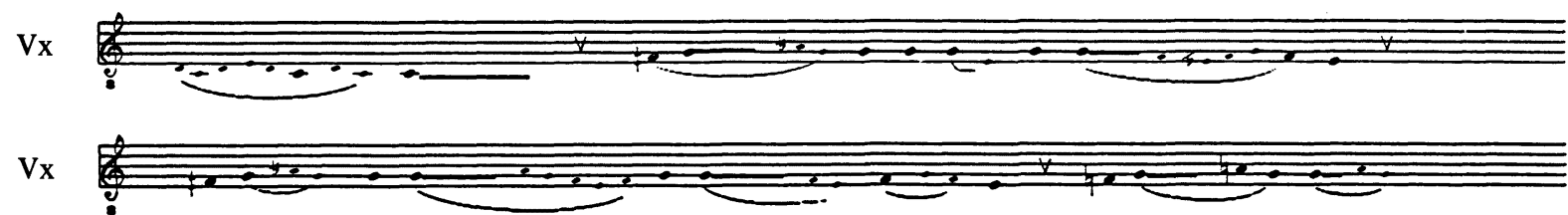

Vx

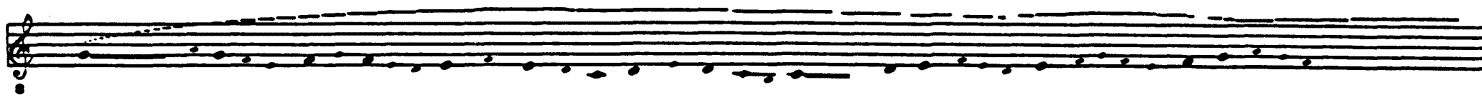

$\mathbf{V x}$

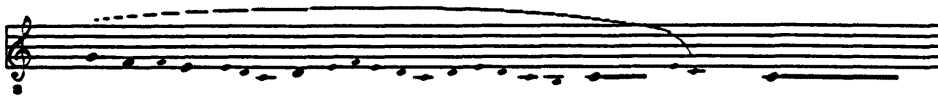


Voix d'homme
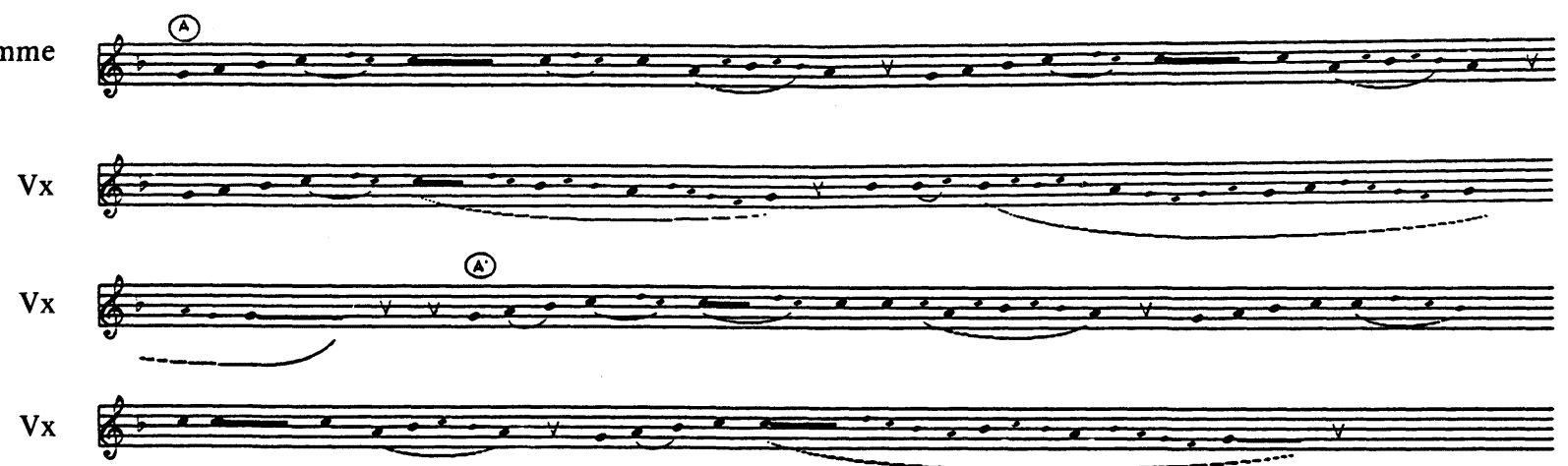

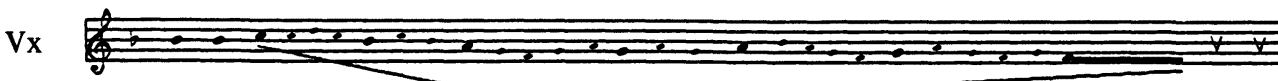




\section{Asturianada, Asturias, región de Llanes}

("Chant long", Asturies région de Llanes)

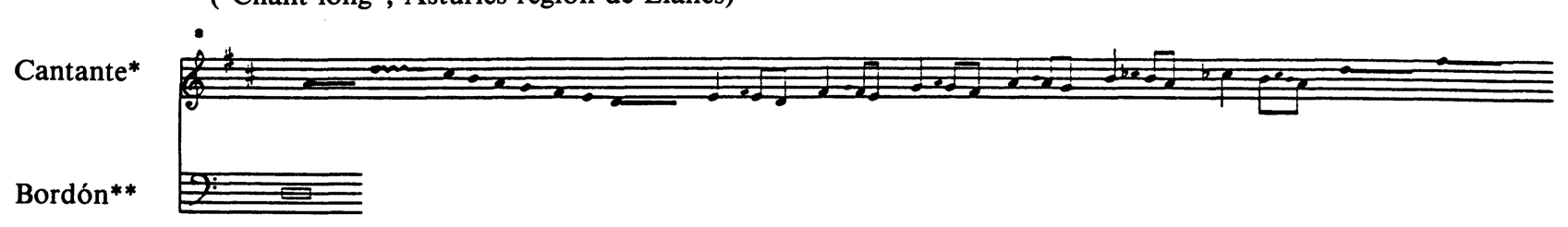

Can.

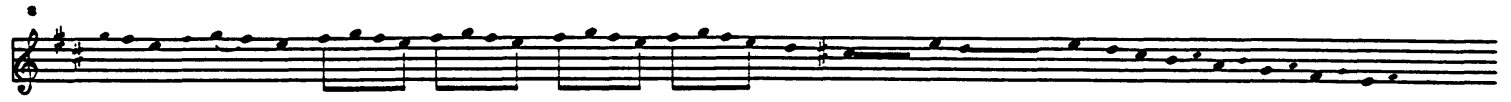

Can.

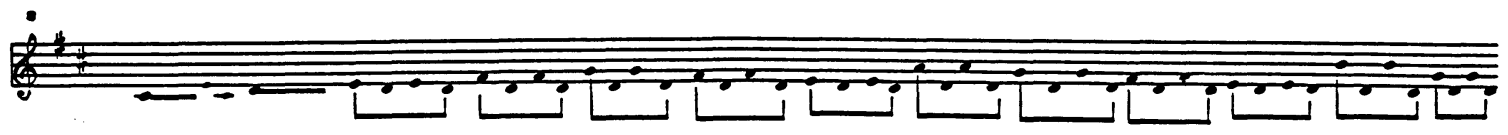

Can.

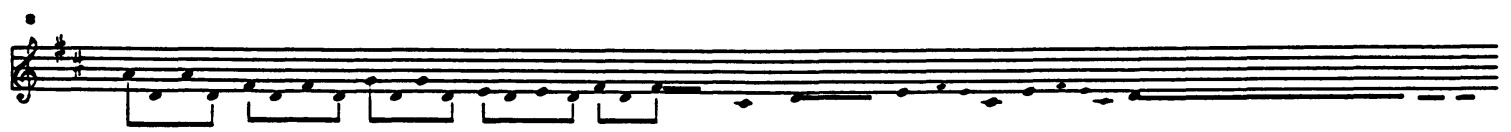

Voix d'homme

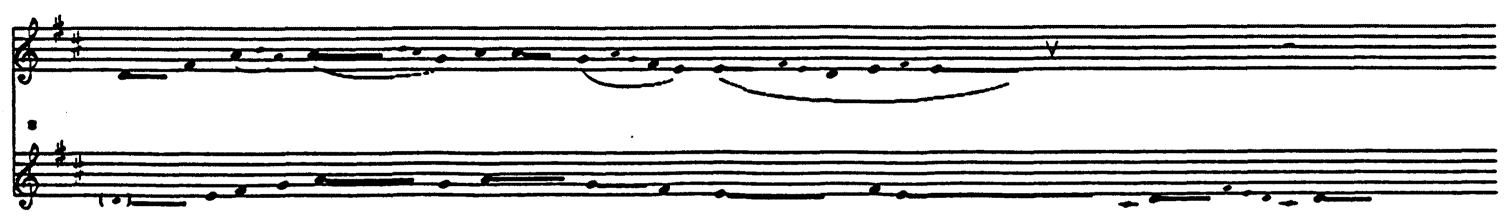


$\breve{\infty}$
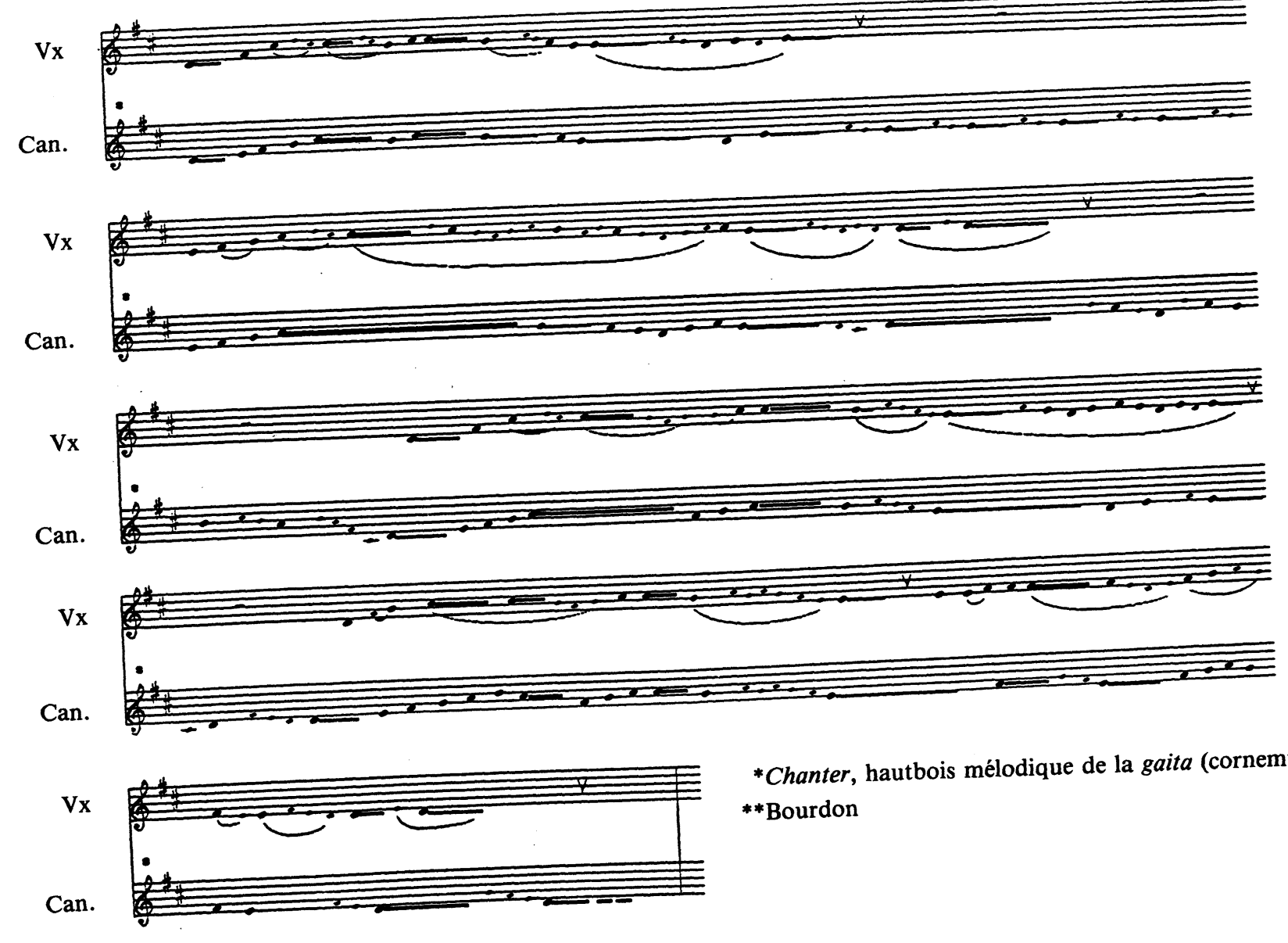

*Chanter, hautbois mélodique de la gaita (cornemuse) **Bourdon 
20. Asturianada, Asturias, región de Oviedo (“Chant long", Asturies, région d'Oviedo)

Cantante*

-

Bordón**

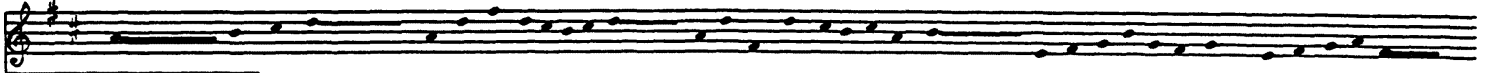

20.

Can.

Can.
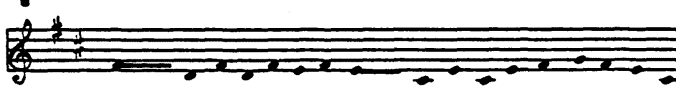

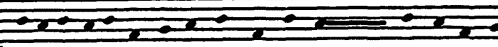

Can.

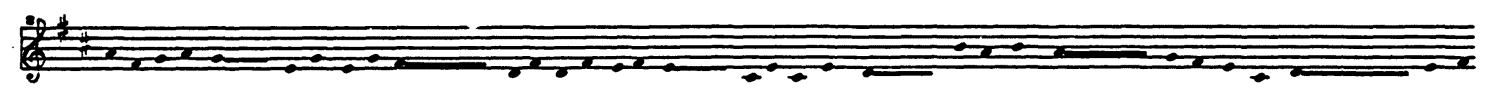

Can.

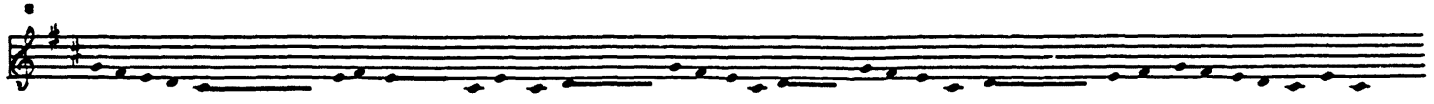


ఫ

Voix de femme
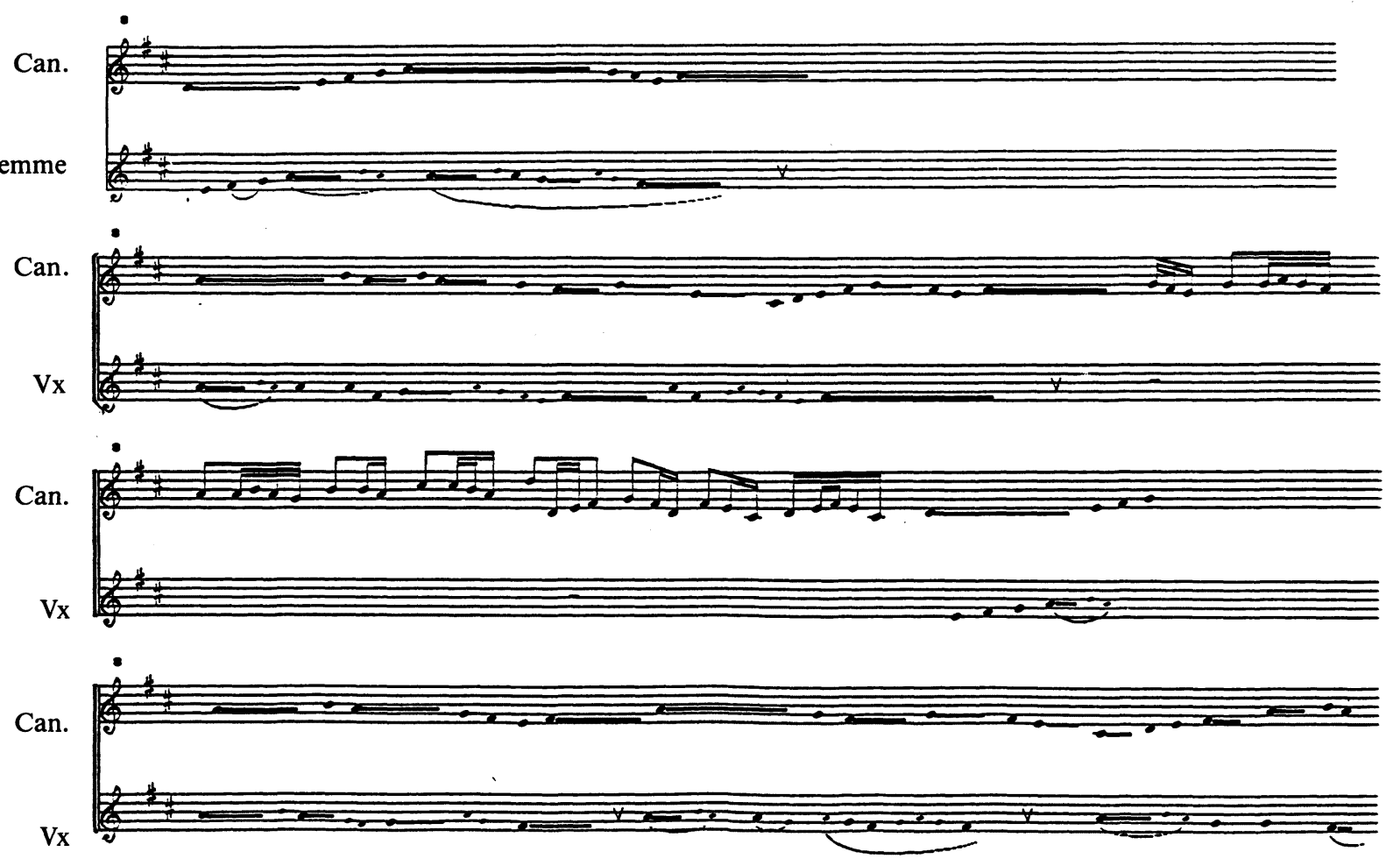


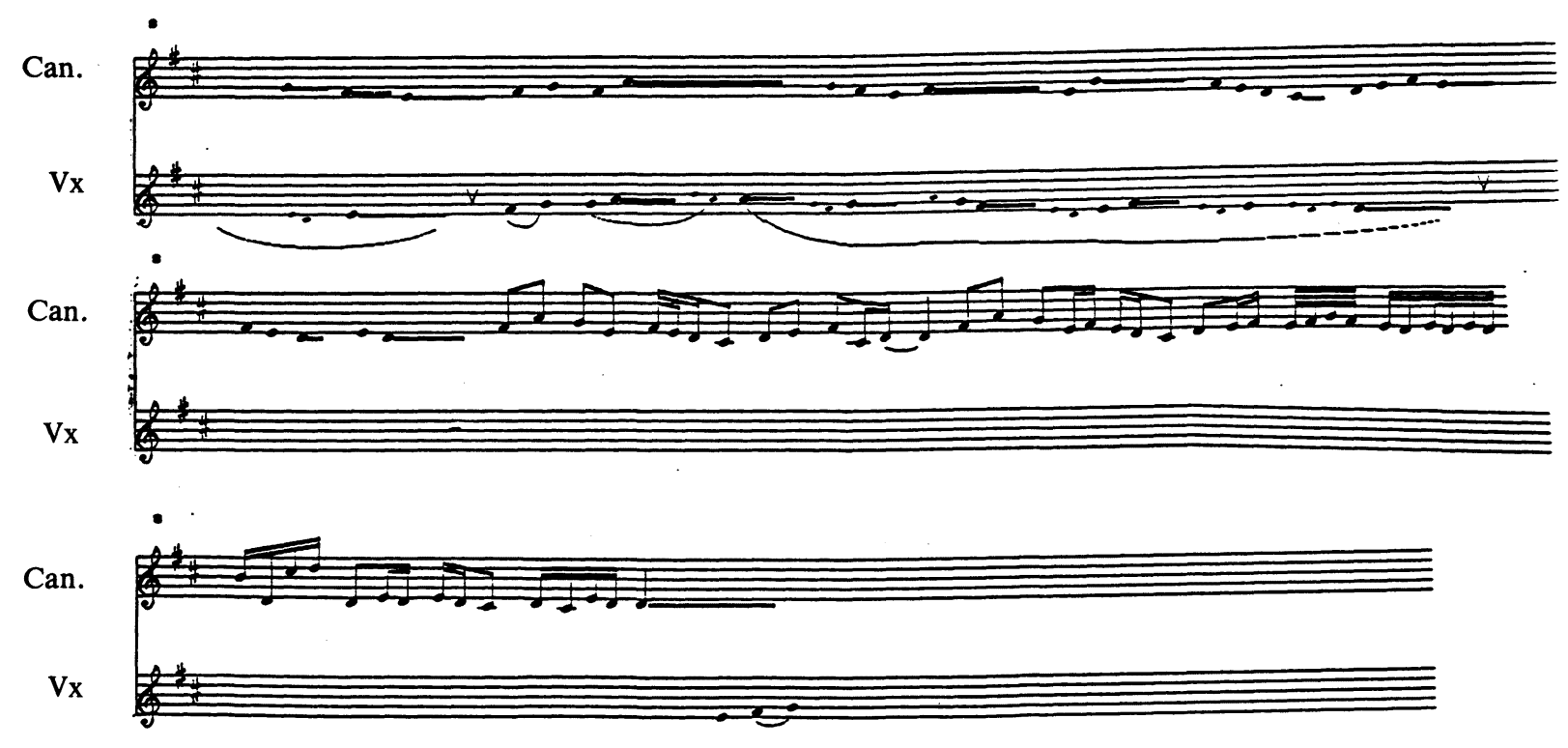

ప્ 
ถู

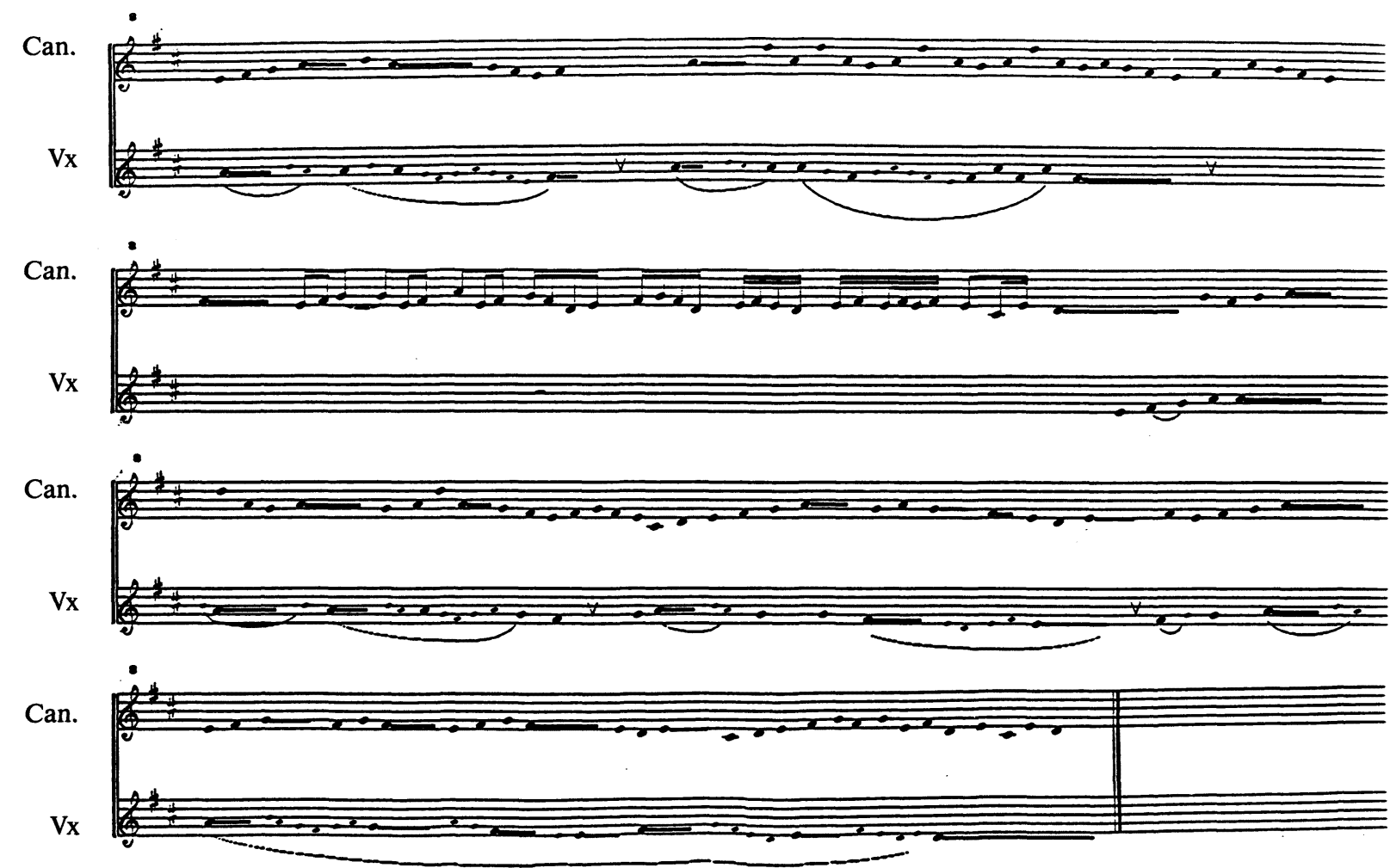

*Chanter, hautbois mélodique de la gaita (cornemuse)

**Bourdon 
21. Asturianada, Asturias, región de Oviedo (“Chant long”, Asturies, région d'Oviedo)

Voix d'homme
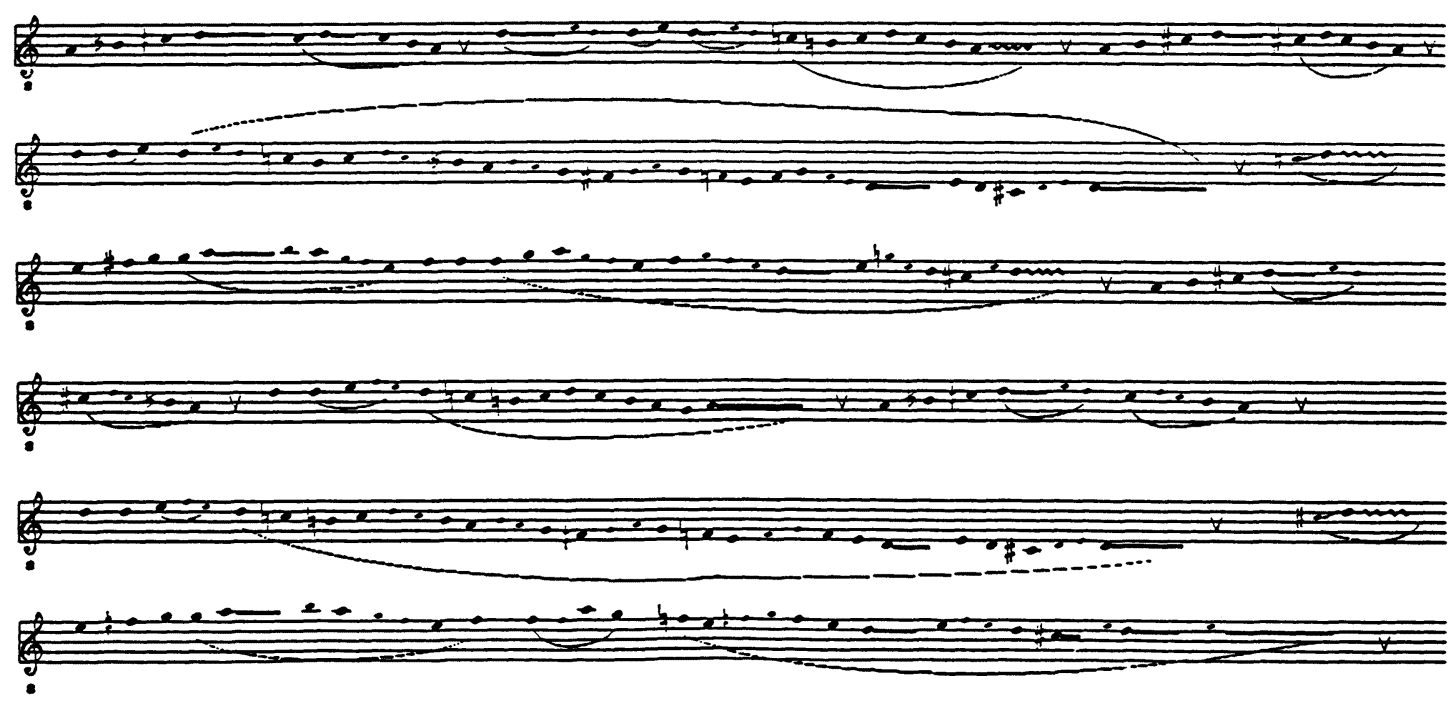
Cantante*

Bordón**

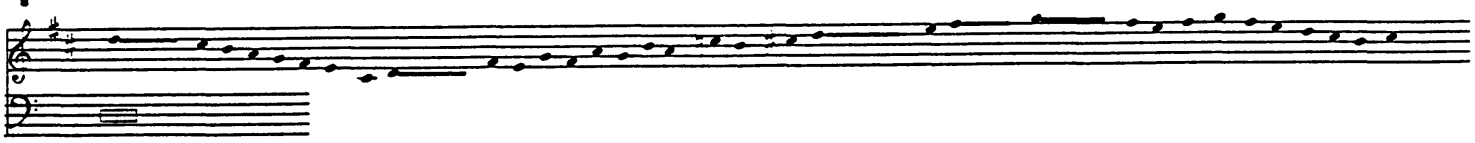

Can.

$$
\text { - }
$$

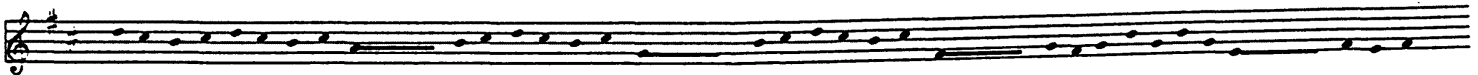

Can.

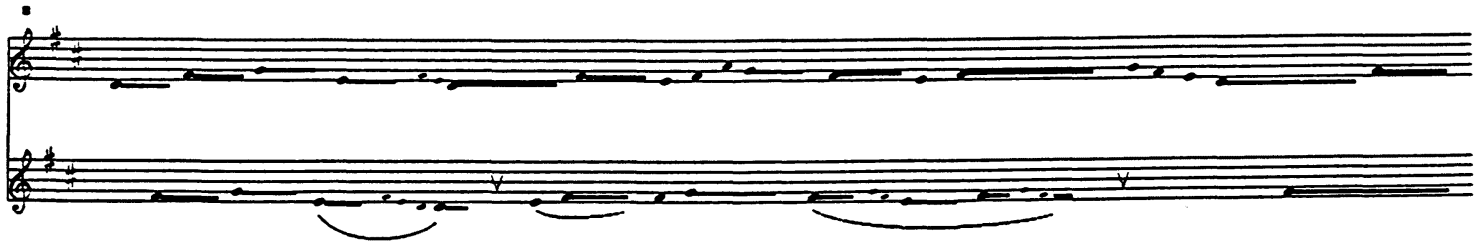

Voix d'homme

Can.

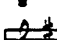

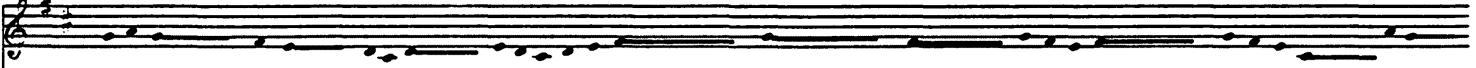

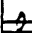

Vx

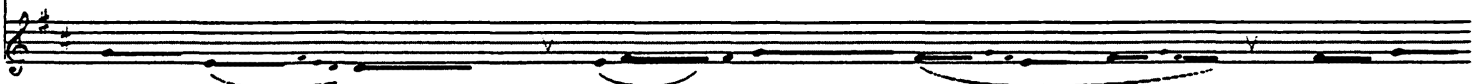




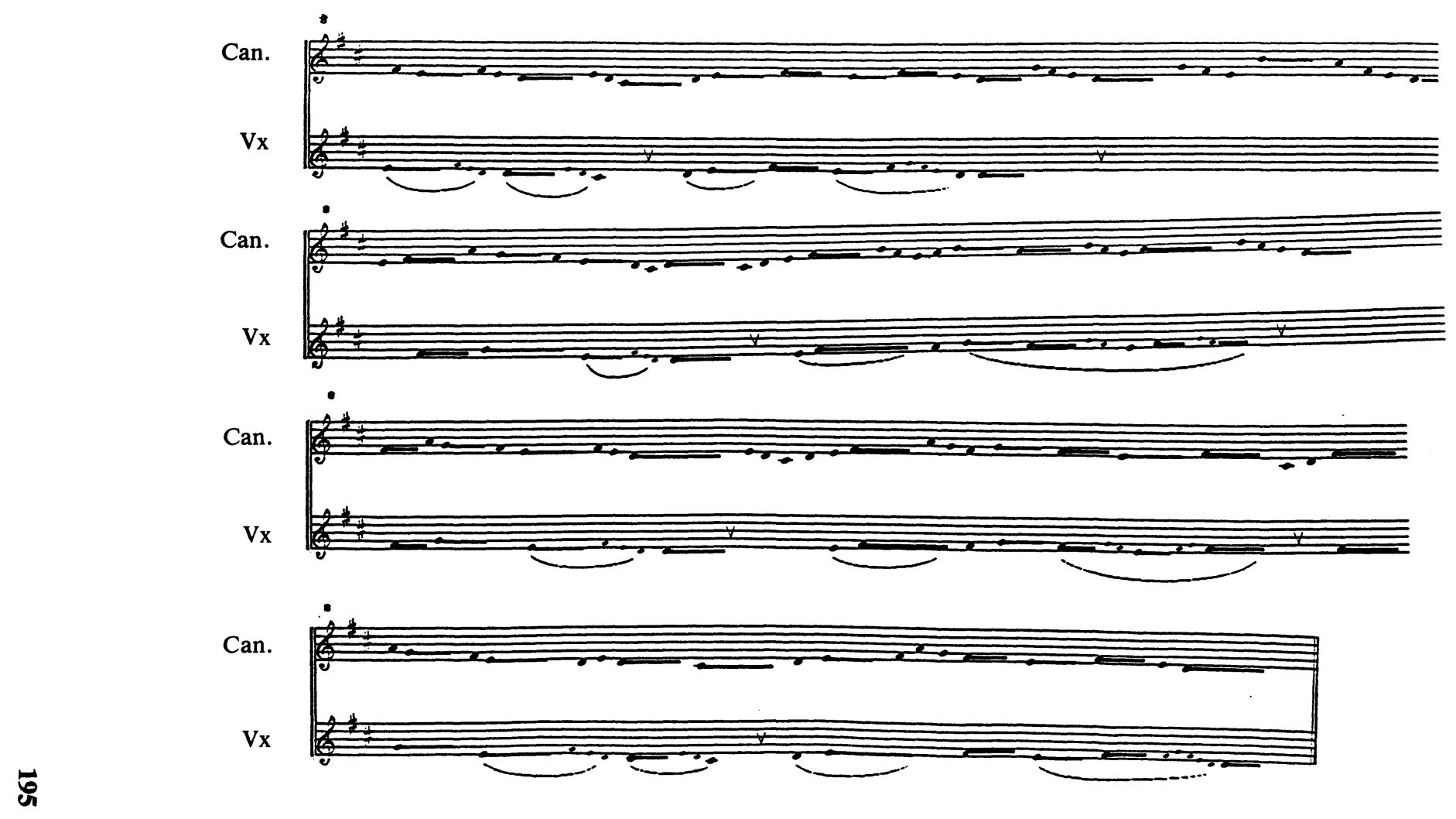

*Chanter, hautbois mélodique de la gaita (cornemuse) 